University of Louisville

ThinkIR: The University of Louisville's Institutional Repository

Electronic Theses and Dissertations

$12-2016$

\title{
An integrated economic equilibrium model for electricity markets.
}

Swapna Pothabathula

University of Louisville

Follow this and additional works at: https://ir.library.louisville.edu/etd

Part of the Engineering Commons

\section{Recommended Citation}

Pothabathula, Swapna, "An integrated economic equilibrium model for electricity markets." (2016). Electronic Theses and Dissertations. Paper 2594.

https://doi.org/10.18297/etd/2594

This Master's Thesis is brought to you for free and open access by ThinkIR: The University of Louisville's Institutional Repository. It has been accepted for inclusion in Electronic Theses and Dissertations by an authorized administrator of ThinkIR: The University of Louisville's Institutional Repository. This title appears here courtesy of the author, who has retained all other copyrights. For more information, please contact thinkir@louisville.edu. 


\title{
AN INTEGRATED ECONOMIC EQUILIBRIUM MODEL FOR ELECTRICITY MARKETS
}

\author{
By \\ Swapna Pothabathula \\ B.TECH., V.R Siddhartha Engineering College, 2013
}

\begin{abstract}
A Thesis
Submitted to the Faculty of the

J.B. Speed School of Engineering of the University of Louisville in Partial Fulfillment of the Requirements

for the Degree of

Master of Science

in Industrial Engineering

Department of Industrial Egnineering

University of Louisville

Louisville, Kentucky
\end{abstract}

December 2016 



\title{
AN INTEGRATED ECONOMIC EQUILIBRIUM MODEL FOR ELECTRICITY MARKETS
}

\author{
By \\ Swapna Pothabathula \\ B.TECH., V.R Siddhartha Engineering College, 2013
}

A Thesis Approved On

November 18th, 2016

by the following Thesis Committee

Dr. Lihui Bai, Thesis Director

Dr. Kihwan Bae

Dr. Thomas Riedel 


\section{ACKNOWLEDGEMENTS}

I would like to express my deepest gratitude to my thesis advisor, Dr. Lihui Bai, for her never ending support and motivation. Her guidance along the way was really valuable and her patience and encouragements never failed to make me feel confident again in the research that I am doing. My sincere thanks to Dr. Thomas Riedel and Dr. Ki-Hwan Gabriel Bae for reviewing and providing some comments to improve this thesis. My appreciation also goes to Dr. John Kielkopf and my friend Guangyang $\mathrm{Xu}$ for their valuable $\mathrm{AT}_{\mathrm{EX}}$ template of the thesis.

My greatest appreciation goes to my beloved parents, Srinivasa Rao and Venkata Ramanamma, my husband Prashant and my brothers for their love and support. Without their trust, I would have never reached this far.

Last but not least, I would like to thank my professors and fellow friends for their support, helpful comments and encouragement. Their help is deeply appreciated. 


\begin{abstract}
AN INTEGRATED ECONOMIC EQUILIBRIUM MODEL FOR ELECTRICITY MARKETS
\end{abstract}

Swapna Pothabathula

November 28th, 2016

The increasing energy challenges worldwide are forcing researchers to explore ways for energy systems that work more efficiently on their own and with each other. This thesis develops an integrated electricity market equilibrium model (EMEM) as a mixed complementarity problem (MCP). In particular, we first develop an equilibrium model to study an electricity market consisting of coal producers, electricity generation firms, natural gas producers, natural gas marketers, natural gas pipeline owners, natural gas consumers and electricity consumers. The equilibrium model not only captures a decentralized optimization for each player but considers the interaction amongst players. Second, we formulate the equilibrium model as a mixed complementarity problem (MCP) and conduct computational studies and sensitivity analyses to shed lights on energy policy making. Numerical results show that the proposed integrated equilibrium model can effectively govern the supply and demand among all players. 


\section{TABLE OF CONTENTS}

Page

ACKNOWLEDGEMENTS

iii

ABSTRACT

LIST OF TABLES

LIST OF FIGURES

\section{CHAPTER}

1 INTRODUCTION 1

2 LITERATURE REVIEW 4

2.1 Optimization Models for Electricity Markets . . . . . . . . . . 4

2.2 Optimization Models for Natural Gas Markets . . . . . . . 5

2.3 Optimization Models for Coal Markets . . . . . . . . . . . . 7

2.4 Optimization Models for Integrated Energy Systems . . . . . . 9

2.5 Formulation of Mixed Complementarity Problems . . . . . . . 10

2.6 The choice of production cost functions for electricity, coal, natural gas and elastic demand . . . . . . . . . . . . . 11

3 THE ELECTRICITY MARKET EQUILIBRIUM MODEL 13

3.1 Notations and Assumptions . . . . . . . . . . . . . . 13

3.2 Mathematical model for Integrated Energy System . . . . . . . 15

4 COMPUTATIONAL RESULTS 24

4.1 Discussions on Parameter and Functions setup . . . . . . . . . . 24

4.2 Results for Energy Market Equilibrium Model (EMEM) without Natural Gas . . . . . . . . . . . . . . . . . . . 26

4.3 Results for Energy Market Equilibrium Model (EMEM) with

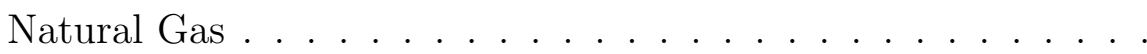


4.4 Results for EMEM with non-electricity natural gas usage . . . . 35

4.5 Sensitivity analysis for EMEM . . . . . . . . . . . . 41

5 CONCLUSION AND FUTURE RESEARCH 50

5.1 Conclusion .................... 50

5.2 Future Research . . . . . . . . . . . . . . 51

REFERENCES $\quad 52$

CURRICULUM VITAE 56 


\section{LIST OF TABLES}

TABLE Page

1 Description of parameters in EMEM . . . . . . . . . . . . . 14

2 Variables and Functions in EMEM . . . . . . . . . . . . 15

3 Heat rate of $u$ and heat content of coal . . . . . . . . . . . . . . 24

4 Shipping prices of coal . . . . . . . . . . . . . . 25

$5 \quad$ Number of hours and days in period $t \ldots \ldots . . . . . . .25$

6 Electricity Sales for EMEM: with CE . . . . . . . . . . . . 28

7 Electricity demand for EMEM: with CE . . . . . . . . . . . . 28

$8 \quad$ Electricity price for EMEM: with CE . . . . . . . . . . . . . . . . . 29

9 Coal price for EMEM: with CE . . . . . . . . . . . . . . . . . 29

10 Electricity demand for EMEM: CNE . . . . . . . . . . . . . . . . . 31

11 Electricity sales for EMEM: CNE . . . . . . . . . . . . . 33

12 Electricity price for EMEM: CNE . . . . . . . . . . . . . . 34

13 Coal price for EMEM: CNE . . . . . . . . . . . . . . . 34

14 Natural gas prices for EMEM: CNE . . . . . . . . . . . . . . . 35

15 Electricity sales for EMEM: CNE-NonE . . . . . . . . . . . . 37

16 Electricity demand for EMEM: CNE-NonE . . . . . . . . . . . . . 37

17 Electricity price for EMEM: CNE-NonE . . . . . . . . . . . . 38

18 Coal price for EMEM: CNE-NonE . . . . . . . . . . . . . . 38

19 Natural gas upstream and midstream prices for EMEM: CNE-NonE . 38

20 Natural gas downstream prices for EMEM: CNE-NonE . . . . . . . . 39

21 Natural gas sales by marketer for EMEM: CNE-NonE . . . . . . . . 40

22 Electricity sales for EMEM: Sensitivity Analysis _ . . . . . . . . . . 42

23 Electricity demand for EMEM: Sensitivity Analysis . . . . . . . . . . 42

24 Coal price for for EMEM: Sensitivity Analysis . . . . . . . . . . . 43 
25 Electricity price for EMEM: Sensitivity Analysis . . . . . . . . . .

26 Electricity price for EMEM: different coefficients of inverse demand function $\left(c_{o}\right) \ldots \ldots \ldots \ldots \ldots \ldots \ldots \ldots \ldots \ldots \ldots \ldots \ldots \ldots$

27 Coal price for EMEM: different coefficients of inverse demand function $\left(c_{o}\right) \ldots \ldots \ldots \ldots \ldots \ldots \ldots \ldots \ldots \ldots \ldots \ldots \ldots \ldots \ldots \ldots \ldots \ldots \ldots$

28 Natural gas transportation rates for EMEM: different coefficients of inverse demand function $\left(c_{o}\right) \ldots \ldots \ldots \ldots \ldots$

29 Downstream natural gas prices for EMEM: different coefficients of inverse demand function $\left(c_{o}\right) \ldots \ldots \ldots \ldots \ldots$

30 Coal price for EMEM: different coefficients of inverse demand function $\left(c_{1}\right) 47$

31 Electricity price for EMEM: different coefficients of inverse demand function $\left(c_{1}\right) \ldots \ldots \ldots \ldots \ldots \ldots \ldots \ldots \ldots$

32 Natural gas transportation rates for EMEM: different coefficients of inverse demand function $\left(c_{1}\right) \ldots \ldots \ldots \ldots$

33 Downstream natural gas prices for EMEM: different coefficients of inverse demand function $\left(c_{1}\right) \ldots \ldots \ldots \ldots$ 


\section{LIST OF FIGURES}

FIGURE $\quad$ Page

1 The network for Electricity Market with Seven Players . . . . . . . 23

2 Coal generation units and electricity generation firms . . . . . . . 27

3 Electricity Market for EMEM: CNE . . . . . . . . . . . . . . . 30

4 Flow of natural gas from producers to electric sector . . . . . . . . . 32

5 Natural gas market after the introduction of NonE sector . . . . . . 36

6 Flow of natural gas from producers to electric and NonE sector . . . 49 


\section{CHAPTER 1}

\section{INTRODUCTION}

With the changing climate and resource scarcity today, the world's energy system is on the verge of a major transformation. Energy systems can refer to Electric power system (supply, transmission and consumption of electric power), thermodynamic system (a physics concept for analysis of thermal energy exchange) and bioenergetics system (metabolic processes for converting energy in living organisms). This thesis deals with electricity markets and components involved in it.

Various technologies are building blocks for the transition to a sustainable energy future. Sustainable energy not only focuses on renewable energy sources such as hydroelectricity, solar energy, wind energy, wave power, geothermal energy, bio-energy, tidal power but also technologies designed to improve energy efficiency. There are various ways in which energy efficiency can be improved; one such way is to integrate various forms of energy in order to achieve the maximum utilization of all the sources involved in integration.

In this thesis, our focus on electric energy market is to improve the efficiency of the overall system. The latter is multi-faceted in nature. For example, electricity can be generated by multiple sources such as coal, natural gas, wind, solar, etc.

Within each generation type, there are multiple market players such as coal producers, coal-fired power generation companies and electric power grid owners for the coal-firing generation. Similarly, nature gas producers, pipeline owners, pipeline operators and power grid owners are key players in the gas-firing generation. In the literature, many researchers have studied optimization models for one player or one subsystem. For example, Kolstad and Abbey [3] examine the effects of market behavior on international steam coal trade while Thompson et al. [4] study natural 
gas storage optimization problems. However, few papers deal with integration of coal and natural subsystems. In our view, only when these subsystems are studied jointly can we accurately assess the overall electricity market and its behavior. Therefore, the research in this thesis aims to fill this gap in the literature by integrating all the components (i.e., subsystems) involved in the electricity market and study the economic equilibrium for this integrated electricity market system.

To further motivate the development of our proposed economic equilibrium model for the electricity market, in the last decade, the electricity industry has experienced significant changes towards deregulation and competition with the aim of improving economic efficiency (see e.g. [1]). When markets are deregulated, pricing of commodities and services should be purely based on market supply and demand. Therefore, an economic equilibrium model and its resulting market-clearing prices can be useful for policy makers to assess the overall system efficiency. Indeed, along the same line of motivation, many have studied equilibrium models in the energy research. For example, Kazempour and Hopkins [5] analyze the impact of large-scale wind power integration on the electricity market equilibrium. As another example, Fuller et al. [6] propose a mathematical model to determine the optimal energy storage systems (ESS) operation as well as the market clearing prices. Our proposed economic equilibrium model is guided by the same principle aiming to offer insights for a deregulated electricity market.

In particular, the proposed economic equilibrium model for electricity markets considers seven types of market players: electricity generation firms that own both coal and gas fired generators, natural gas producers, natural gas pipeline operators, natural gas marketers, and coal mine owner, and finally electricity consumers and natural gas consumers. All generation and services are subject to fixed and deterministic capacities, while consumer demands for electricity are elastic. We develop mathematical models that each player (or subsystem) wishes to optimize and then integrate these optimized subsystems into an equilibrium model by using market-clearing conditions to represent the interaction between pairs of players. In other words, the market equilibrium model optimizes each of the 
individual components (i.e. electricity sector, natural gas sector and coal sector) and ensures that the market clearing conditions are satisfied whenever the individual components interact with each other. It is important to note that, as by products, the market-clearing prices for the equilibrium model offer guidelines for commodity pricing such as electricity price at demand region and coal prices for different regions in the electricity market.

The contribution of this thesis is two-fold. First, we develop an equilibrium model to study an electricity market consisting of coal producers, electricity generation firms, natural gas producers, natural gas marketers, natural gas pipeline owners, natural gas consumers and electricity consumers. The equilibrium model not only captures a decentralized optimization for each player but considers the interaction amongst players. Second, we formulate the equilibrium model as a mixed complementarity problem (MCP) and conduct various sensitivity analyses to shed lights on energy policy making.

The rest of this thesis is organized as follows. Chapter 2 reviews the literature on the electricity market, coal market, natural gas market and equilibrium models in electricity market. Chapter 3 formulates the mathematical models for each of the components involved in the electricity market. Chapter 4 presents the computational experiments and their results and conclusions and future research are presented in Chapter 5. 


\section{CHAPTER 2}

\section{LITERATURE REVIEW}

In this chapter, we review the body of research in the operations research literature that is closely related to our research in this thesis. This review is divided into five parts on: electricity market optimization, natural gas market optimization, coal market optimization, integrated energy systems and finally the applications of mixed complementarity problems, respectively.

\subsection{Optimization Models for Electricity Markets}

Optimization of electricity markets is widely studied by many researchers with various objectives or constraints. For example, Hobbs [7] considers imperfect competition among electricity producers. This paper focuses on developing a linear complementarity model of the Nash-Cournot competition in bilateral and POOLCO power markets (A POOLCO is a privatized power exchange that operates auctions, hosts spot market sales and generally functions as a privately owned market place for energy sales in the wholesale marketplace). The model is formulated as mixed linear complementarity problem. The model considers two types of players, i.e., electricity producers and grid owners, and its solutions are essentially the imperfectly competitive equilibria. Similarly, Cardell et al. [15] present a work on market power and strategic interaction in electricity markets. This paper presents a model where a firm no longer exercises market power by restricting its own production. This model constrains the electrical network where generator exercises market power by increasing its production in order to block transmission. The players in the model are Cournot firms and a collection of competitive fringe participants. This model illustrates the possible strategic interactions between the 
players. Furthermore, Ramos et al. [16] model the competitive behavior of electric firms by incorporating equilibrium constraints. These constraints provide characterization of the first order optimality conditions of strategic companies. The objective of this approach is to maximize profit while meeting the equilibrium constraints.

One other stream of research in the electricity market optimization studies the market power of various players. For example, Kahn et al. [17] model the electric markets for estimating the price or cost margins; however, they conclude that the model may not be able to tell whether a firm or set of firms can succeed in manipulating market prices. Borenstein et al. [19] provide an an empirical analysis of the potential for market power in Californias electricity industry. The model in this paper shows the two most important factors in determining the extent and severity of market power. The factors are available hydroelectric production and the elasticity of demand. The model indicates that there is potential for significant market power during high demand hours (where elastic demand comes into picture). Finally, Helman et al. [18] present a strategic pricing model in bilateral and Poolco electricity markets by using Nash-Cournot approach and use the U.S. eastern interconnection as a case study. This paper has two specific models a Nash-Cournot framework and represents transmission constraints by a linearized DC network. The formulation in this model helps in computation for larger markets while guaranteeing the existence of unique price equilibria. As mentioned previously, the above literature mainly focuses on electricity markets optimization, but notintegrated energy system as a whole. The major difference between these literatures and the current thesis is that we study an integrated energy equilibrium model that includes coal market, electricity market, natural gas market and elastic demand.

\subsection{Optimization Models for Natural Gas Markets}

Natural gas markets optimization is not new in the literature but they have generally focused on either optimization of gas operations or computation of market equilibrium prices, flows and quantities. We review several papers in this area. 
Some works present natural gas market equilibrium model that involves natural gas market alone. For instance, Gabriel et al. [8] discuss mixed complementarity based equilibrium model of natural gas markets. This paper presents a natural gas market equilibrium model that has producers, storage reservoir operators, peak gas operators, pipeline operators, marketers and consumers. The equilibrium model is an instance of a mixed nonlinear complementarity problem for natural gas market (NCP). The NCP formulation is derived from considering the Karush-Kuhn- Tucker optimality conditions of the optimization problems faced by these participants. The natural gas equilibrium model is validated by considering nine market participants, three seasons and using four scenarios. Similarly, Zhuang et al. [20] discuss a large-scale complementarity model of the North American natural gas market. This paper analyses the natural gas market using a linear complementarity equilibrium model. The players considered are producers, storage and peak gas operators, third party makers and end user sectors. The model is validated based on National Petroleum Council scenarios. Few researches also study natural gas optimization models with main focus on cost minimization. Avery et al. [21] develop an optimization model for purchase, storage and transmission contracts for natural gas utilities. The model minimizes cost while satisfying regulatory agencies and presents a decision support system for natural gas utilities to plan operations. The model considers wellhead, consumers, transport and storage as its players.

Additionally, there are few works that consider optimization techniques to meet natural gas demand. Zheng et al. [22] model the natural gas markets for meeting the demand. The players considered are natural gas producers, transportation network, and market (consumers). Optimization techniques are widely used to meet the demand for natural gas and have yielded a lot of promising results. The pipeline network for natural gas markets is also widely studied. There are optimization models for dimensioning of pipeline networks. De Wolf et al. [23] present optimal dimensioning of pipe networks with applications to gas transmission networks. While all these works deal either with natural gas market in a decentralized fashion or develop an equilibrium model for natural gas market alone, 
our thesis presents an equilibrium model for electricity markets and its players as an integrated system.

\subsection{Optimization Models for Coal Markets}

Coal was the first fossil fuel used for heat and power. Coal consumption declined as oil and natural gas replaced coal in heating, electric engines, steam engines and motors. Throughout the long period in decline of coal consumption, electric utilities expanded their use of coal enormously.

There are quite a lot of models that discuss minimization of costs for fuel inputs, forecasts of coal prices, coal production and consumption. There are programming models for coal markets that analyze the demand for coal. Labys et al. [25] present a quadratic programming model of the Appalachian steam coal market. The authors attempt to analyze the Appalachian steam coal market using a programming approach. The destinations of Appalachian coals have been determined on the basis for the demand for steam coal created by major utility companies. This model determines the extent to which Appalachian coal can meet eastern US steam coal demands by minimizing costs of fuel inputs. Energy Information Administration [EIA] developed a mathematical model for computer implementation of the National Coal Model [26]. This report contains the objectives used in the development of the National Energy Modeling System (NEMS) Coal market Module. The conceptual and methodological approach is used for the development of this system. The CMM provides annual forecast of prices, production, and consumption of coal for the NEMS. The CMM has two submodules Coal Production Submodule (CPS) and Coal Distribution Submodule (CDS). The CPS provides supply inputs that are integrated by the CDS to satisfy demands for coal received from demand models. The CDS forecasts annual world coal trade flows from major supply to major demand regions and provides annual forecasts of U.S coal exports for input into NEMS. This work completely focuses on forecasts of prices, production and consumption of COAL only.

There are few works that formulates an equilibrium model for coal markets. 
Haftendorn et al. [10] models to assess international coal markets until 2030. This paper presents an equilibrium model of international market for steam coal. The players considered in this model are producers and exporters. This equilibrium model is formulated in the complementarity format. This model is tested by using a base case scenario and suggestions for alternative scenarios. Franziska et al [28] model and analyse the International Steam Coal trade. This paper presents the analysis of prices and trade flows for steam coal in the international market. This is done by simulating the market for a couple of years using the complementarity modeling technique. The paper presents two models 1) quality based model for coal and 2) a model that incorporates energy values. The conclusion of this paper is that an energy-based model is more superior than a quality based model.

Complementarity format discussed in these two works Haftendorn et al. [10] and Franziska Holz et al [28] exactly fits into a part of the work done for this thesis.

Furthermore, there are transportation models in the literature review for coal markets. LeBlanc [27] formulates a transportation Model for the US Coal Industry. This work presents a general economic model that minimizes the cost of coal shipments in the United States. The economic model described is a linear programming model. This model assumes coal demand and sulfur dioxide emission regulations. The results of the model indicate significant differences in flows and shadow prices under varied assumptions. As Demand plays a vital role in any supply chain, there are literature reviews that model for coal demand. Labys et al. [25] and Maggi et al. [29] has their work on development and perspectives on supply and demand in the global hard coal market. They discuss the root causes for the extreme price developments of coal and provides insights on changing supply and demand structure within the seaborne hard coal market. Maggi et al. [29] build analytical methods for the development and perspectives on supply and demand in the global hard core market. These are few literature reviews that model coal market by itself for various reasons mentioned but none of them consider modelling two or more different systems/entities and solve for equilibrium. 


\subsection{Optimization Models for Integrated Energy Systems}

Integrated energy systems play a vital role in efficient energy planning and sustainable development. There are very few works in the literature review that consider modelling the energy system as a whole. Quelhas et al. [9] present a multi-period generalized network model of the U.S. integrated energy system. It is a multi-period generalized network flow model of the integrated energy system in the United States. The players considered in the model are coal and natural gas suppliers to the electric load centers. The mathematical model is developed by connecting the electricity demand nodes and fuel supply via a transportation network. The model incorporates production, storage and transportation of coal, natural gas and electricity in one mathematical framework. The model is solved for the most efficient allocation of quantities and corresponding prices. The objective of the proposed model is to minimize the total costs which include fuel production cost, fuel transportation costs, fuel storage costs, electricity generation costs and electricity transmission costs. It also provides numerical results which describes the application of proposed model. There are few literature reviews that consider modelling the integrated energy systems for economic studies. Gil et al. [30] develop an integrated energy transportation networks for analysis of economic efficiency and network interdependencies. This paper presents an integrated mathematical framework for coal, gas, water, and electricity production and transportation. The model named as the National Electric Energy System (NEES) is formulated using a network flow optimization model. It is modelled fundamentally by balancing energy at various nodes such as production nodes, storage nodes, generation nodes and electric transmission nodes. The objective function is set to minimize the total cost in the entire framework. The solution for this model is an algorithm anchored in the network simplex method. Also, McCalley et al. [31] model an integrated energy system for determining nodal prices. This is a generalized network flow model for integrated energy systems. This model is used to analyze the economic interdependencies of energy systems. This model comprises multiple entities such as 
electric network and fuel supply and delivery systems. The model is solved using an optimization algorithm that also provides nodal prices as a byproduct. These nodal prices provide a way to analyze the economic interdependencies between the various fuel networks and the electric network. (Nodal pricing is defined as a method of determining prices in which market clearing prices are calculated for a number of locations on the transmission grid called as nodes).

However, all the above researches are trying to model the integrated energy systems but none of them considers the competition among participants. Hence, in this thesis we intend to develop an integrated economic equilibrium model for electricity markets that consider electricity market (production and transmission), elastic demand of electricity by consumers, natural gas market (upstream natural gas producers, midstream natural gas pipeline owners, downstream natural gas marketers) and coal market (coal producers) along with market clearing conditions that serve as binding bridge among these players.

\subsection{Formulation of Mixed Complementarity Problems}

In our thesis, optimization models are developed for each of the players involved in the integrated energy system. All these players are interconnected to each other by market clearing conditions. These individual optimization models are modelled into a single equilibrium model by formulating into a mixed complementarity problem. There are few works in the literature review that use a similar approach for modelling. Few such literatures are Cottle et al. [33] explain the formulation of linear complementarity problem. Similarly, Gabriel et al. [37] present complementarity modeling in Energy markets. This book presents clear picture of the modeling advantages of complementarity problems vs optimization and standard models. Modelling for equilibrium constraints is seen in some literature reviews, Luo et al. [35] model mathematical programs with equilibrium constraints. This paper mentions the method for binding various players using equilibrium constraints which is used as an example in our thesis. Dirks et al. [34] has a collection of nonlinear mixed complementarity problems. This paper explains 
the formulation for nonlinear mixed complementarity problems which is used for nonlinear cost functions in my thesis.

After developing the mathematical model for the integrated energy system as a whole, it is tested for numerical results and validation. General Algebraic Modeling System (GAMS) is one such mathematical modelling language used by many researchers. Ferris et al. [32] describe complementarity problems in GAMS and the PATH solver. This paper presents the method to find a solution for a square system of nonlinear equations by converting them into complementarity problem. This paper explains the methodology for solving such problems in GAMS and provides details about the PATH solver for finding the solution. There are also works on extensions of GAMS for complementarity problems arising in applied economic analysis. All of the above cited literature has been used to implement the developed integrated energy equilibrium model into GAMS and obtain numerical results.

2.6 The choice of production cost functions for electricity, coal, natural gas and elastic demand

The production cost functions for coal, natural gas and electricity have been widely cited in many literature reviews. Few such researches have been studied during the course of our thesis. Bhagwat et al. [38] develop a report on cost of underground coal mining in Illinois. This report has been used as reference for coal production cost function. They presents a linear production cost function for coal that depend on various factors such as annual production, age of mines, labor productivity, mine development cost, coal cleaning level. On considering the typical values for all these factors, a constant value has been determined. The final coal transportation cost used in our thesis has turned out to be a linear cost function.

Gabriel et al. [8] develop a mixed complementarity-based equilibrium model of natural gas markets. This paper has been used a reference for production cost function of electricity and natural gas. The electricity production cost function is a linear function and is used as such. The natural gas cost function is modified 
according to the units considered in my thesis.

For elastic demand, there are quite a lot of literature reviews major them being traffic models. Dafermos [39] presents a multimodal network equilibrium problem with elastic demand. It defines the concepts of user-optimality and equilibrium. The algorithm proceeds by iteration, each step of which amounts to computing the equilibrium pattern for a single modal linear traffic equilibrium problem with elastic demands. Arnott et al. [40] develop a structural model of peak-period congestion. This paper considers the modeling of road congestion subject to peak-load demand. The model treats elastic (i.e., price-sensitive) demand and examines some economic implications of the structural approach. There are very few works that consider elastic demand in energy markets and are mainly seen in bidding strategies for electricity markets Wang et al. [41]. In this paper they propose an evolutionary imperfect information game approach to analyze bidding strategies in electricity markets with price-elastic demand. All of the above cited literature have been used as a basis for elastic demand function used in our thesis. 


\section{CHAPTER 3}

\section{THE ELECTRICITY MARKET EQUILIBRIUM MODEL}

In this chapter, we discuss the mathematical model behind EMEM. This chapter is divided into two parts on: notations and assumptions, and mathematical model for integrated energy system.

\subsection{Notations and Assumptions}

As mentioned previously, we consider an electricity market consisting of seven elements: power generation firms that own both coal-firing and gas-firing generators, coal producers, natural gas producers, natural gas pipeline owners, natural gas marketers, natural gas consumers and electricity consumers. The relationships between these elements are as follows. First, electricity and natural gas consumers are represented by electricity demand nodes $(i)$ and natural gas demand regions $(j)$, respectively. Second, each natural gas producer $n$ belongs to a natural gas supply region $w$ through a mapping function $\tau(n)=w$, and each coal producer $m$ belongs to a coal supply region $v$ through a mapping function $\tau(m)=v$. Third, each generation unit $u$ belongs to a generation firm $f$ through a mapping function $o(u)=f$. Additionally, unit $u$ has a designated generation technology $h(u)$ to indicate the coal type if coal-firing or if it is gas-firing and a designated transmission network through a mapping function $\theta(u)$. Finally, we consider two uses $k=1,2$ of natural gas: generating electricity or others including industrial, commercial and residential. They have separate demands at each natural gas demand region $j$. These elements each has associated attributes. A generation unit $u$ is associated with its unique heat rate (MMBTU/MWh), heat content (MMBTU/short ton), non-fuel related marginal costs $(\$ / \mathrm{MWh})$, production cost $(\$ / \mathrm{MWh})$, and capacity 
(MW). Furthermore, natural gas producer and coal producer each has production capacity. For natural gas pipeline owner, each pipeline $l$ has its origin, destination regions as well as capacity $(\mathrm{MCF})$. Figure 1 provides a schematic illustration for a small integrated system and Table 1 summarizes the sets, indices and parameters for these components used in our model.

\begin{tabular}{|c|c|}
\hline$i=1, \ldots, I$ & electricity demand nodes \\
\hline$j=1, \ldots, J$ & natural gas demand regions \\
\hline$n=1, \ldots, N$ & natural gas producers \\
\hline$w=1, \ldots, W$ & natural gas producer locations \\
\hline$\tau(n)$ & $\begin{array}{l}\text { mapping of natural gas producer } n \\
\text { to its location (i.e., } \tau(n)=w, w=1, \ldots, W \text { ) }\end{array}$ \\
\hline$\omega(n)$ & $\begin{array}{l}\text { mapping of natural gas producer } n \text { to its supply region } w \\
\text { (i.e., } \omega(n)=w, w=1, \ldots, W)\end{array}$ \\
\hline$m=1, \ldots, M$ & coal mine owners \\
\hline$v=1, \ldots, V$ & coal mine locations \\
\hline$\tau(m)$ & $\begin{array}{l}\text { mapping of coal mine owner } m \text { to its location } \\
\text { (i.e., } \tau(m)=v, v=1, \ldots, V)\end{array}$ \\
\hline$\tau(u)$ & $\begin{array}{l}\text { mapping of coal unit } u \text { to its coal supply region } \\
\text { (i.e., } \tau(u)=v, v=1, \ldots, V)\end{array}$ \\
\hline$f=1, \ldots, F$ & power generation firms, with each firm possibly owning several units \\
\hline$u=1, \ldots, U$ & generation units \\
\hline$o(u)$ & mapping of a generation unit $u$ to its owner $f$ (i.e., $o(u)=f$ ) \\
\hline$h(u)$ & electricity generation technology of unit $u$ (coal, natural gas); \\
\hline$k=1, \ldots, K$ & fuel consumption sectors (electricity, industrial, commercial, residential) \\
\hline$o(k)$ & mapping of sector $k$ (eg. $o(k)=1$ means that $k$ is electricity sector) \\
\hline$a=1, \ldots, A$ & natural gas marketers \\
\hline$l=1, \ldots, L$ & natural gas pipelines \\
\hline$o(l), d(l)$ & the origin and destination of pipeline $l$ \\
\hline$H R_{u}$ & heat rate of generation unit $u$ [MMBTU/MWh] \\
\hline$H C_{c}$ & heat content of coal type $c$ [MMBTU/short ton] \\
\hline$C_{u}(\cdot)$ & non-fuel related marginal costs for generation unit $u[\$ / \mathrm{MWh}]$ \\
\hline$C_{n}(\cdot)$ & production cost for natural gas producer $n[\$ / \mathrm{MCF}]$ \\
\hline $\bar{X}_{u}$ & capacity of generation unit $u[\mathrm{MW}]$ \\
\hline $\bar{G}_{n}$ & natural gas production upper bound for producer $n[\mathrm{MCF}]$ \\
\hline$\underline{L}_{l}$ & pipeline $l$ capacity $[\mathrm{MCF}]$ \\
\hline$Z_{m}$ & capacity of coal mine $m$ [short ton] \\
\hline$t$ & time periods \\
\hline$H_{t}$ & number of hours in period $t$ \\
\hline$D_{t}$ & number of days in period $t$ \\
\hline
\end{tabular}

TABLE 1

\section{Description of parameters in EMEM}

The equilibrium model is driven by the maximization of the total utility of electricity and natural gas consumers. It will determine, while respecting capacity 
constraints at various player sites, the production levels for electricity generation units, natural gas producers and coal producers, and the flows from coal producers to generation units, from natural gas producers to pipelines then to generation units, from natural gas producers to pipelines then to natural gas demand regions, and from generation units to electricity demand regions. Table 2 summarizes the variables representing these quantities and some associated function used in the mathematical model.

\begin{tabular}{ll}
\hline$x_{u t}$ & electricity generated by unit $u$ in time $t[\mathrm{MW}]$ \\
$s_{u i t}$ & electricity sales by unit $u$ to demand region $i$ in time $t[\mathrm{MW}]$ \\
$g_{n t}$ & natural gas produced by producer $n$ in time $t$ [MCF $/$ period] \\
$z_{m t}$ & coal produced by owner $m$ in time $t$ [short ton/period] \\
$q_{a w j k t}$ & natural gas bought by marketer $a$ from supply region $w$ \\
& to ship to region $j$, sector $k$ in time $t$ [MCF/period] \\
$f_{l t}$ & natural gas flow through pipeline $l$ \\
$p_{w t}^{g}$ & upstream (wellhead) natural gas prices at region $w$ in time $t[\$ / \mathrm{MCF}]$ \\
$p_{j k t}^{g}$ & downstream natural gas prices paid by consumers \\
$P_{j k t}^{g}(\cdot)$ & in region $j$, sector $k$ in time $t[\$ / \mathrm{MMBU}]$ \\
$p_{t}^{l}$ & natural gas transportation rates for pipeline $l$ in time $t[\$ / \mathrm{MCF}]$ \\
$p_{v t}^{c}$ & coal prices for region $v$ coal in time $t$ [\$/short ton] \\
$p_{v o(u)}^{s}$ & shipping cost of transporting coal from coal mine region $v$ \\
& to the region of generation unit $u[\$ /$ short ton] \\
$p_{i t}^{e}$ & electricity price at demand region $i[\$ / \mathrm{MWh}]$ \\
$P_{i t}^{e}(\cdot)$ & inverse demand function of electricity at node $i$ in time $t[\$ / \mathrm{MWh}]$ \\
$d_{i t}^{e}$ & electricity demand at region $i$ in time $t[\mathrm{MW}]$
\end{tabular}

TABLE 2

Variables and Functions in EMEM

\subsection{Mathematical model for Integrated Energy System}

In this section, we examine each players optimization problem first, and then present the integrated equilibrium model. First, optimization problem for generation firm $f^{\prime} s$ is discussed. Firm $f$ objective function is defined as maximization of its profit. The first term $\sum_{i} H_{t} p_{i t}^{e} s_{u i t}$ represents the revenue of $f$ generated by total sales of electricity by $u$ to node $i$ at $t . C_{u}\left(H_{t} x_{u t}\right)$ is the cost for generation of electricity for $u$. These two terms are summed over those generation units $u$ that belong to firm $f$. Cost incurred due to natural gas is represented by 
$p_{\tau(u) E t}^{g} H_{t} H R_{u} x_{u t}$ and is summed over natural gas fired generation units. Cost for purchasing coal is defined as $p_{h(u) t}^{c}\left(H R_{u} / H C_{h(u)}\right) x_{u t} H_{t}$ and cost for shipping coal is defined as $p_{v o(u)}^{s}\left(H R_{u} / H C_{h(u)}\right) x_{u t} H_{t}$. Both of these terms are summed over coal fired generation units $u$ that belong to firm $f$. Hence, profit for firm $f$ is defined as revenue minus sum of all costs. The constraint $s_{u i t}=x_{u t}$ means that electricity generated by $u$ at $t$ is equal to sales of electricity by $u$ to $i$ at $t$ summed over all demand nodes $i$.

Electricity generation firm $f$ :

$$
\begin{array}{ll}
\max & \sum_{t}\left\{\sum_{u: o(u)=f}\left[\sum_{i} H_{t} p_{i t}^{e} s_{u i t}-C_{u}\left(H_{t} x_{u t}\right)\right]-\sum_{u: h(u)=\text { gas }} p_{\tau(u) E t}^{g} H_{t} H R_{u} x_{u t}-\right. \\
& \left.\sum_{u: h(u)=\text { coal }}\left[p_{h(u) t}^{c}\left(H R_{u} / H C_{h(u)}\right) x_{u t} H_{t}+p_{v o(u)}^{s}\left(H R_{u} / H C_{h(u)}\right) x_{u t} H_{t}\right]\right\} \\
\text { s.t. } & \sum_{i} s_{u i t}=x_{u t}, \quad \forall t, \forall u: O(u)=f\left(\lambda_{u t}\right) \\
& s_{u i t}, x_{u t} \geq 0,
\end{array}
$$

Consumer's utility optimization problem is defined as follows. The objective function tries to maximize their amount of electricity for least amount of money.

The first term $\sum_{t} \sum_{i} \int_{0}^{d_{i t}^{e}} P^{e}\left(\mu_{i t}\right) d \mu_{i t}$ is the inverse demand function integrated over electricity demand $d_{i t}^{e}$. It is the price at which customers are willing to pay for electricity. The second term $\sum_{t} \sum_{i} p_{i t}^{e} d_{i t}^{e}$ is the actual price for electricity demanded. Electricity consumers utility maximization:

$$
\begin{array}{ll}
\max & \sum_{t} \sum_{i} \int_{0}^{d_{i t}^{e}} P^{e}\left(\mu_{i t}\right) d \mu_{i t}-\sum_{t} \sum_{i} p_{i t}^{e} d_{i t}^{e} \\
\text { s.t. } & d_{i t}^{e} \geq 0,
\end{array}
$$

Supply must always be equal to demand and following equation represents it. It is the market clearing condition between electricity generators and consumers. Electricity market clearing condition:

$$
d_{i t}^{e}=\sum_{u} s_{u i t}, \forall i, t \quad \cdots p_{i t}^{e}
$$


Next, optimization problem for coal producers is discussed. The term $\sum_{t} p_{\tau(m) t}^{c} z_{m t}$ represents revenue generated by coal producer $m$ by selling $z_{m t}$ shortton of coal at price $p_{\tau(m) t}^{c}$. Cost for production of coal is represented as $C_{m}\left(z_{m t}\right)$. The constraint $z_{m t}$ less than or equal to $\bar{Z}_{m}$ says that coal production is limited to a certain capacity.

Coal mine owner $m$ :

$$
\begin{array}{ll}
\max & \sum_{t} p_{\tau(m) t}^{c} z_{m t}-\sum_{t} C_{m}\left(z_{m t}\right) \\
\text { s.t. } & z_{m t} \leq \bar{Z}_{m}, \quad\left(\gamma_{m t}\right) \\
& z_{m t} \geq 0
\end{array}
$$

Total coal produced by all producers $m$ must be utilized for generation of electricity. The mathematical form for this market clearing condition is defined as follows. Coal market clearing condition:

$$
\sum_{m: \tau(m)=v} z_{m t}=\sum_{u: h(u)=\operatorname{coal}, \tau(u)=v}\left(H R_{u} / H C_{h(u)}\right) x_{u t} H_{t}, \quad \forall v, t \quad\left(p_{v t}^{c}\right)
$$

Natural gas producer optimization problem is discussed as follows. Like coal and electricity players, natural gas also has similar objective function. The term $\sum_{t} D_{t} p_{w(n) t}^{g} g_{n t}$ represents the revenue for producer $n$ generated by selling natural gas at a price of $g_{n t}$. The production cost is defined as $\sum_{t} D_{t} C_{n}\left(g_{n t}\right)$. Natural gas producer $n$ is allowed to produce up to certain capacity $\bar{G}_{n}$.

Natural gas producer $n$ :

$$
\begin{aligned}
& \max \sum_{t} D_{t} p_{w(n) t}^{g} g_{n t}-\sum_{t} D_{t} C_{n}\left(g_{n t}\right) \\
& \text { s.t. } g_{n t} \leq \bar{G}_{n}, \quad\left(\delta_{n t}\right) \\
& g_{n t} \geq 0,
\end{aligned}
$$

Natural gas produced by all the producers $n$ that belong to region $w$ must be equal to the amount of natural gas bought by marketers $a$ from supply region $w$ to ship to regions $j$, sectors $k$ in time $t$. This market clearing condition is mathematically defined as follows. 
Upstream Natural gas market clearing condition:

$$
\sum_{n: w(n)=w} g_{n t}=\sum_{a} \sum_{j} \sum_{k} q_{a w j k t}, \quad \forall w, t \quad\left(p_{w t}^{g}\right)
$$

Natural gas pipeline operator $l$ maximization problem depends on flow through pipeline $l$ and natural gas transportation rates for pipeline $l$ in time $t$. The flow through pipeline $l\left(f_{l t}\right)$ is restricted with an upper bound capacity of $L_{l}$. Natural gas pipeline operator $l$ :

$$
\begin{array}{ll}
\max & \sum_{t} D_{t} p_{t}^{l} f_{l t} \\
\text { s.t. } & f_{l t} \leq L_{l}, \forall t \quad\left(\alpha_{l t}\right) \\
& f_{l t} \geq 0,
\end{array}
$$

Market clearing condition for midstream pipeline market is merely flow conservation principle. Flow through pipeline $l$ at time $t$ must be equal to natural gas bought by marketers $a$ from supply regions $w$ to ship to regions $j$, sectors $k$ in time $t$. Mathematically, it can be represented as follows.

Midstream pipeline market clearing condition:

$$
f_{l t}=\sum_{a} \sum_{k} q_{a o(l) d(l) k t} \forall l, t \quad\left(p_{t}^{l}\right)
$$

For natural gas marketer $a, \sum_{t} \sum_{j} \sum_{k} D_{t} p_{j k t}^{g} \cdot\left(\sum_{w} q_{a w j k t}\right)$ represents revenue generated by selling natural gas to consumers. Cost for buying natural gas from producers is shown as $\sum_{t} \sum_{w} D_{t} p_{w t}^{g} \cdot\left(\sum_{j} \sum_{k} q_{a w j k t}\right)$ and cost for natural gas transforation is $\sum_{t} D_{t} p_{t}^{l} \cdot\left(\sum_{l} \sum_{k} q_{a o(l) d(l) k t}\right)$. Hence, maximization problem for marketer $a$ is defined as follows. 
Natural gas marketer $a$ :

$$
\begin{aligned}
\max & \sum_{t} \sum_{j} \sum_{k} D_{t} p_{j k t}^{g} \cdot\left(\sum_{w} q_{a w j k t}\right)-\sum_{t} \sum_{w} D_{t} p_{w t}^{g} \cdot\left(\sum_{j} \sum_{k} q_{a w j k t}\right)- \\
& \sum_{t} D_{t} p_{t}^{l} \cdot\left(\sum_{l} \sum_{k} q_{a o(l) d(l) k t}\right)
\end{aligned}
$$

s.t. $\quad q_{a w j k t} \geq 0$,

Market clearing condition for downstream natural gas is similar to coal market clearing condition, i.e. Total natural gas produced must be utilised by both electric and non-electric sectors. For $k=$ electric sector, $30 \%$ of natural gas produced must be fully utilized for production of electricity. For $k=$ non - electric sector, $70 \%$ of natural gas must be utilized by non-electric sector. Mathematical form for this is defined as follows.

Downstream natural gas consumption market clearing condition:

$$
\begin{aligned}
& \sum_{a} \sum_{w} 1.028 \cdot D_{t} q_{a w j k t}=\sum_{u: o(u)=j, h(u)=\mathrm{gas}} H_{t} H R_{u} x_{u t}, \forall j, t, k=\operatorname{elec} \operatorname{sector}\left(p_{j k t}^{g}\right) \\
& \sum_{a} \sum_{w} q_{a w j k t}=(7 / 3) \sum_{a} \sum_{w} \sum_{k: k=\text { elec sector }} q_{a w j k t}, \forall j, t, k=\text { non }-\operatorname{elec} \operatorname{sector} \quad\left(p_{j k t}^{g}\right)
\end{aligned}
$$

Individual optimization problems for coal, electricity and natural gas markets are integrated into equilibrium model by using market clearing conditions. This model is presented as mixed complementarity problem (MCP) by using Karush Kuhn Tucker (KKT) conditions and Lagrangian Equations. $L^{f}(x, s ; \lambda)$ represents Lagrangian Equation for electricity markets. $\frac{\partial L^{f}}{\partial s_{u i t}}$ is the first order derivative of Lagrangian Equation w.r.t positive variable $s_{u i t}$. Similarly, $\frac{\partial L^{f}}{\partial x_{u t}}$ is the first order derivative w.r.t positive variable $x_{u t}$. Likewise, $L^{c}(d), L^{n}(g ; \delta), L^{l}(f ; \alpha), L^{a}(q)$ and $L^{m}(z ; \gamma)$ are Lagrangian Equations for consumer's utility, natural gas producers, natural gas pipeline owners, natural gas marketers and coal producers respectively. The first order derivatives of all Lagrangian Equations w.r.t positive variables form MCP and are shown under Lagrangian Equations. 


\begin{tabular}{ll}
\hline Parameters & $H_{t}$ \\
& $H R_{u}$ \\
& $H C_{h(u)}$ \\
& $p_{v o(u)}^{s}$ \\
& $\bar{Z}_{m}$ \\
& $D_{t}$ \\
\hline Positive Variables & $x_{u t}$ \\
& $s_{u i t}$ \\
& $d_{i t}^{e}$ \\
& $z_{m t}$ \\
& $g_{n t}$ \\
& $f_{l t}$ \\
& $q_{a w j k t}$ \\
& $C_{u}\left(H_{t} x_{u t}\right)$ \\
& $C_{m}\left(z_{m t}\right)$ \\
& $P^{e}(\cdot)$ \\
& $C_{n}\left(g_{n t}\right)$ \\
\hline Functions
\end{tabular}

$\underline{\text { Lagrangian Equations: }}$

$$
\begin{aligned}
& L^{f}(x, s ; \lambda)=-\sum_{t}\left\{\sum_{u: o(u)=f}\left[\sum_{i} H_{t} p_{i t}^{e} s_{u i t}-C_{u}\left(H_{t} x_{u t}\right)\right]-\sum_{u: h(u)=\mathrm{gas}} p_{\tau(u) k t}^{g} H_{t} H R_{u} x_{u t}\right. \\
& \left.-\sum_{u: h(u)=\text { coal }}\left[p_{v t}^{c}\left(H R_{u} / H C_{h(u)}\right) x_{u t} H_{t}+p_{v o(u)}^{s}\left(H R_{u} / H C_{h(u)}\right) x_{u t} H_{t}\right]\right\} \\
& +\sum_{t} \sum_{u: o(u)=f}\left[\lambda_{u t} \cdot\left(x_{u t}-\sum_{i} s_{u i t}\right)\right] \\
& \left.\frac{\partial L^{f}}{\partial s_{u i t}}\right|_{u: o(u)=f}=0 \Longrightarrow-H_{t} p_{i t}^{e}-\lambda_{u t}=(\geq) 0 \\
& \left.\frac{\partial L^{f}}{\partial x_{u t}}\right|_{u: o(u)=f, h(u)=\mathrm{coal}, h(u) \neq \text { gas }}=0 \Longrightarrow \frac{\partial C_{u}\left(H_{t} \cdot x_{u t}\right)}{\partial\left(H_{t} \cdot x_{u t}\right)} \cdot H_{t} \\
& +p_{\tau(u) t}^{c} \cdot\left(H R_{u} / H C_{h(u)}\right) \cdot H_{t}+p_{\tau(u) o(u)}^{s} \cdot\left(H R_{u} / H C_{h(u)}\right) \cdot H_{t}+\lambda_{u t}=(\geq) 0 \\
& \left.\frac{\partial L^{f}}{\partial x_{u t}}\right|_{u: o(u)=f, h(u) \neq \mathrm{coal}, h(u)=\mathrm{gas}}=0 \Longrightarrow \frac{\partial C_{u}\left(H_{t} \cdot x_{u t}\right)}{\partial\left(H_{t} \cdot x_{u t}\right)} \cdot H_{t}+p_{\tau(u) k t}^{g} \cdot H_{t} H R_{u}+\lambda_{u t}=(\geq) 0
\end{aligned}
$$




$$
\begin{array}{r}
L^{c}(d)=-\sum_{t} \sum_{j} \int_{0}^{d_{i t}^{e}} P^{e}\left(\mu_{i t}\right) d \mu_{i t}+\sum_{t} \sum_{i} p_{i t}^{e} d_{i t}^{e} \\
\left.\frac{\partial L^{c}}{\partial d_{i t}^{e}}\right|_{u: o(u)=f}=0 \Longrightarrow-P^{e}\left(d_{i t}^{e}\right)+p_{i t}^{e}=(\geq) 0
\end{array}
$$

$$
\begin{array}{r}
L^{n}(g ; \delta)=-\sum_{t} D_{t} p_{w t}^{g} g_{n t}+\sum_{t} D_{t} C_{n}\left(g_{n t}\right)+\sum_{t} \delta_{n t}\left(g_{n t}-\bar{G}_{n}\right) \\
\frac{\partial L^{n}}{\partial g_{n t}}=0 \Longrightarrow-D_{t} p_{w t}^{g}+D_{t} \frac{\partial C_{n}\left(g_{n t}\right)}{\partial g_{n t}}+\delta_{n t}=(\geq) 0
\end{array}
$$

$$
\begin{array}{r}
L^{l}(f ; \alpha)=-\sum_{t} D_{t} p_{t}^{l} f_{l t}+\sum_{t} \alpha_{l t}\left(f_{l t}-\bar{L}_{l}\right) \\
\frac{\partial L^{l}}{\partial f_{l t}}=0 \Longrightarrow-D_{t} p_{t}^{l}+\alpha_{l t}=(\geq) 0
\end{array}
$$

$$
\begin{aligned}
L^{a}(q)=-\sum_{t} \sum_{j} \sum_{k} 1.028 D_{t} p_{j k t}^{g} \cdot\left(\sum_{w} q_{a w j k t}\right) & +\sum_{t} \sum_{w} D_{t} p_{w t}^{g} \cdot\left(\sum_{j} \sum_{k} q_{a w j k t}\right) \\
& +\sum_{t} D_{t} p_{t}^{l} \cdot\left(\sum_{l} \sum_{k} q_{a o(l) d(l) k t}\right) \\
\frac{\partial L^{a}}{\partial q_{a w j k t}}=0 \Longrightarrow & -D_{t} p_{j k t}^{g}+D_{t} p_{w t}^{g}+D_{t} p_{t}^{l}=(\geq) 0
\end{aligned}
$$

$$
\begin{array}{r}
L^{m}(z ; \gamma)=-\sum_{t} p_{\tau(m) t}^{c} z_{m t}+\sum_{t} C_{m}\left(z_{m t}\right)+\sum_{t} \gamma_{t}\left(Z_{m t}-\bar{Z}_{m}\right) \\
\frac{\partial L^{m}}{\partial z_{m t}}=0 \Longrightarrow-p_{\tau(m) t}^{c}+\frac{\partial C_{m}\left(z_{m t}\right)}{\partial z_{m t}}+\gamma_{m t}=(\geq) 0
\end{array}
$$




\begin{tabular}{|c|c|c|c|c|c|c|c|c|c|c|c|}
\hline $\begin{array}{l}\text { Variables } \\
\text { Constraints }\end{array}$ & $\begin{array}{l}s_{u i t} \\
(16)\end{array}$ & $\begin{array}{l}x_{u i t} \\
(17)(18)\end{array}$ & $\begin{array}{l}d_{i t}^{e} \\
(19)\end{array}$ & $\begin{array}{l}g_{n t} \\
(20)\end{array}$ & $\begin{array}{l}f_{l t} \\
(21)\end{array}$ & $\begin{array}{l}q_{a w j k t} \\
(22)\end{array}$ & $\begin{array}{l}z_{m t} \\
(23)\end{array}$ & & $\begin{array}{l}\gamma_{m t} \\
(6)\end{array}$ & $\begin{array}{l}\delta_{n t} \\
(9)\end{array}$ & $\begin{array}{l}\alpha_{l t} \\
(12)\end{array}$ \\
\hline $\begin{array}{l}\text { Variables } \\
\text { Constraints }\end{array}$ & $\begin{array}{l}p_{i t}^{e} \\
(4)\end{array}$ & $\begin{array}{l}p_{v t}^{c} \\
(7)\end{array}$ & $\begin{array}{l}p_{w t}^{g} \\
(10)\end{array}$ & $\begin{array}{l}p_{t}^{l} \\
(13)\end{array}$ & $\begin{array}{l}p_{j k t}^{g} \\
(15)\end{array}$ & & & & & & \\
\hline Complementarity & \multicolumn{11}{|c|}{$\begin{array}{l}\text { positive variables: } x_{u t} \geq 0, s_{u i t} \geq 0, d_{i t}^{e} \geq 0, g_{n t} \geq 0, f_{l t} \geq 0 \\
q_{a w j k t} \geq 0, z_{m t} \geq 0, \gamma_{m t} \geq 0, \delta_{n t} \geq 0, \alpha_{l t} \geq 0 \\
\text { free variable }\left(\lambda_{u t}\right) \text { matches with equality constraints }\end{array}$} \\
\hline
\end{tabular}

Table shown above lists the relationship between constraints and variables in MCP.

For example, $s_{\text {uit }}$ is tied to Equation $16, p_{i t}^{e}$ shadow price for electricity and is tied to Equation 4. Likewise all the variables that are related to their respective constraints are briefed in this table. 


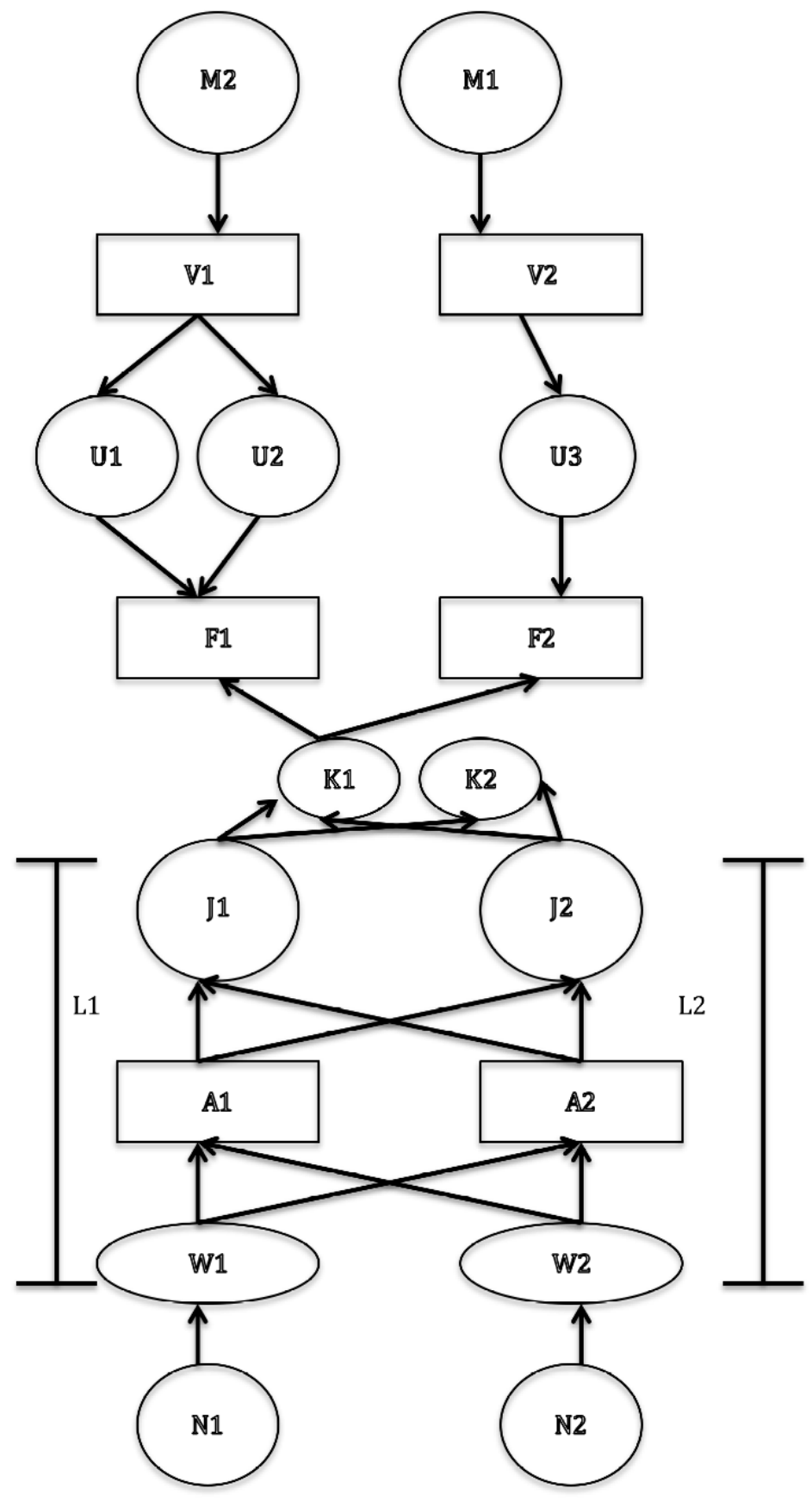

Figure 1. The network for Electricity Market with Seven Players 


\section{CHAPTER 4}

\section{COMPUTATIONAL RESULTS}

In this chapter we present the numerical results for EMEM model. This chapter is divided into five parts on: parameters and functions setup, EMEM without natural gas, EMEM with natural gas,EMEM with natural gas and non-electric sector, sensitivity analysis on EMEM.

\subsection{Discussions on Parameter and Functions setup}

We evaluate the proposed equilibrium model in the MCP format through simulation using the PATH solver in GAMS (General Algebraic Modeling System). In this section we discuss parameters and functions used in the model. Table 3 shows heat rate and heat content of coal for generation units $u$. Heat content for generation units $u_{4}$ and $u_{5}$ is not specified since they are natural gas fired units. Table 4 shows the shipping cost of transporting coal from coal mine region $v$ to the region of generation unit $u$. These values are based on those published by the EIA $[13]$.

\begin{tabular}{c|c|c}
\hline$u$ & $H R_{u}(\mathrm{MMBTU} / \mathrm{MWh})$ & $H C_{h(u)}(\mathrm{MMBTU} /$ shortton $)$ \\
\hline 1 & 10.089 & 19.21 \\
2 & 9.86 & 21.28 \\
3 & 11.91 & 18.96 \\
4 & 7.0 & \\
5 & 7.5 & \\
\hline
\end{tabular}

TABLE 3

Heat rate of $u$ and heat content of coal

Coal producers are limited to certain capacity of producing coal at any given time period $t$. Bhagwat et al. [38] generate a report on coal production capacities in 


\begin{tabular}{c|c|c}
\hline$v$ & $u$ & $p_{v o(u) t}^{s}(\$ /$ shortton $)$ \\
\hline 1 & 1 & 5 \\
1 & 2 & 3 \\
2 & 3 & 6 \\
\hline
\end{tabular}

TABLE 4

Shipping prices of coal

various parts of the U.S. Using this report, coal producer $m_{1}$ is limited to a capacity of 100,000 short ton/t and coal producer $m_{2}$ is limited to a capacity of 120,000 short ton/t. Similarly, capacities for pipelines $l_{1}$ and $l_{2}$ are set to be 2,740 MCF/day and $1,860 \mathrm{MCF} /$ day respectively [14]. The Number of hours in a given time period $t$ is set around a month. Table 5 shows number of hours and number of days in time $t$.

\begin{tabular}{c|c|c}
\hline$t$ & $H_{t}$ (Number of hours) & $D_{t}$ (Number of days) \\
\hline 1 & 700 & 30 \\
2 & 660 & 28 \\
3 & 600 & 25 \\
\hline
\end{tabular}

TABLE 5

Number of hours and days in period $t$

There are several important functions in the proposed model. First, $P_{j t}^{e}(\cdot)$ is inverse demand function of electricity at node $j$ in time $t[\$ / \mathrm{MWh}]$ and is set as $P_{j t}^{e}(\cdot)=c_{o}-c_{1} d_{i t}^{e}\left(c_{o}=60, c_{1}=0.1\right)$. Second, $C_{u}(\cdot)$ is non-fuel related marginal costs for generation unit $u[\$ / \mathrm{MWh}]$ and is set as $C_{u}(\cdot)=0.0002 x_{u t}$ in reference with Gabriel et al. [8]. Third, $C_{m}(\cdot)$ is production cost for coal producer $m$ [\$/shorttons] and is set as $C_{m}(\cdot)=31 z_{m t}$ in reference with Bhagwat et al. [38]. The cost per ton of clean coal as defined in the report is $C_{m}(\cdot)=44.22-\left(1.9085 \times 10^{-6}\right) x_{1}$ $-0.19906 x_{2}-\left(6.3166 \times 10^{-3}\right) x_{3}+\left(6.4903 \times 10^{-2}\right) x_{4}+0.75955 x_{5}$ where $x_{1}=$ annual production (tons per year), $x_{2}=$ age of mine (years), $x_{3}=$ labor productivity (tons per worker per year), $x_{4}=$ mine development cost (dollars per ton annual production), $x_{5}=$ coal cleaning level. On considering the typical values for $x_{2}, x_{3}$, $x_{4}$ and $x_{5}$ from the graphs as 12,2500, 30 and 3 respectively, the final constant value turned out to be 31.02 . This results in the final production cost per unit to be 
$C_{m}(\cdot)=31-\left(1.9085 \times 10^{-6}\right)$ (annual production). Hence, the final total monthly cost is set to be $C_{m}(\cdot)=31$ (monthly production) $-\left(1.9085 \times 10^{-6}\right)(12)$ (monthly production $)^{2}$. In order to ignore non-convexity nature of the production cost function, it is considered as linear function, $C_{m}(\cdot)=31$ (monthly production). Fourth, $C_{n}(\cdot)$ is the production cost for natural gas producer $n[\$ / \mathrm{MCF}]$ is set to be $C_{n}(\cdot)=0.005 g_{n t}+0.000003 g_{n t}^{2}$ in reference with Gabriel et al. [8]. Although our numerical experiments use $\mathrm{MCF} /$ day in the natural gas production, this production cost is validated and produced similar results as in Gabriel et al. [8].

4.2 Results for Energy Market Equilibrium Model (EMEM) without Natural Gas

The mixed complementarity problem (MCP) that has been developed using KKT conditions is numerically tested using parameters and functions as described in Section 4.1. This section deals with the equilibrium model that has coal and electricity as players. The numerical example that is considered for testing this model has two electricity generation firms $f_{1}, f_{2}$, three electricity generation units $u_{1}, u_{2}$, two coal mine regions $v_{1}, v_{2}$ and two coal producers $m_{1}, m_{2}$. Figure 2 shows the schematic diagram that describes the interconnection between players. For instance, generation unit $u_{1}$ and generation unit $u_{2}$ belong to electricity generation firm $f_{1}$. Similarly, $u_{1}$ and $u_{2}$ are served by coal producer $m_{2}$ through coal mine region $v_{1}$. In these tables, it has to be noted that suffix $C E$ means the model with coal and electricity at equilibrium. There are other suffixes to be introduced in later sections for other modelling scenarios.

Table 6 shows electricity sales by generation unit $u$ to electricity demand region $i$ in time $t$. Generation units $u_{1}$ and $u_{2}$ belong to generation firm $f_{1}$ and receives its coal from coal producer $m_{2}$. The model chooses $u_{2}$ and not $u_{1}$ for generation of electricity for firm $f_{1}$. This is because $u_{2}$ is more efficient than $u_{1}$ (efficiency of generation unit is inversely proportional to the ratio of heat rates and heat contents). From Table 3 it can be seen that the ratio of $H R_{u}(\mathrm{MMBTU} / \mathrm{MWh})$ to $H C_{h(u)}$ (MMBTU/shortton) for generation unit $u_{1}$ is 0.4634 and for generation unit $u_{2}$ is 0.5251 . Generation unit $u_{3}$ produces electricity irrespective of its 

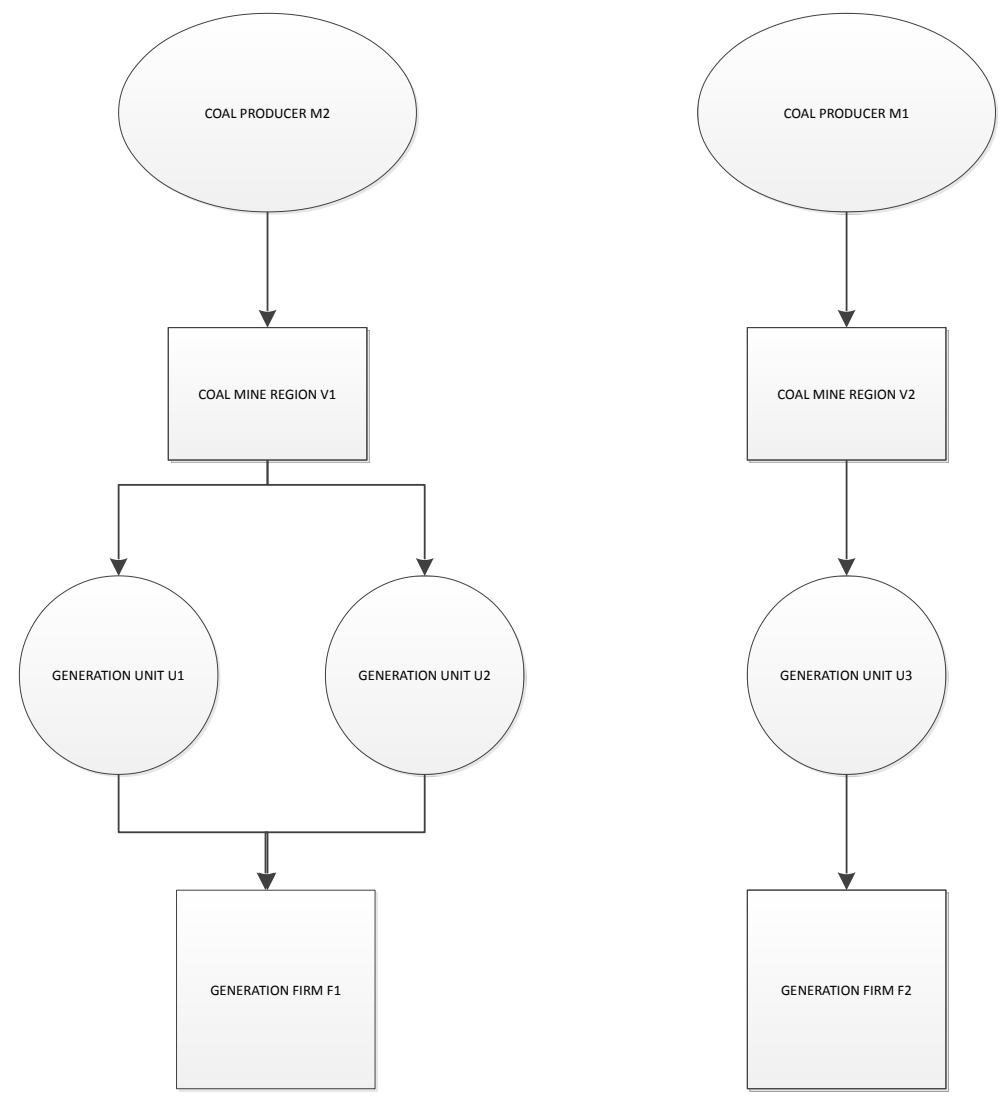

Figure 2. Coal generation units and electricity generation firms

efficiency (since it is the only generation unit for firm $f_{2}$ ). Also, it can be seen that sales of electricity by generation unit $u_{1}$ to demand node $i_{1}$ at time $t_{1}$ is 185 Megawatts and that of unit $u_{1}$ to node $i$ at time $t_{2}$ is 196 Megawatts. It varies with time because generation of electricity is inversely proportional to number of hours in each time period. Table 5 shows that there are 700 hours in $t_{1}$ and 660 hours in $t_{2}$. The demand nodes $i_{1}, i_{2}$ and $i_{3}$ are all identical and hence receive same amount of electricity at give time time $t$ from generation unit $u$.

The equilibrium model shows that coal producers $m_{1}$ and $m_{2}$ produce coal to 


\begin{tabular}{ccc|c||ccc|c}
\hline$u$ & $i$ & $t$ & $s_{u i t} \mathrm{CE}(\mathrm{MW})$ & $u$ & $i$ & $t$ & $s_{\text {uit }} \mathrm{CE}(\mathrm{MW})$ \\
\hline 1 & 1 & 1 & 0 & 2 & 2 & 1 & 185 \\
1 & 1 & 2 & 0 & 2 & 2 & 2 & 196 \\
1 & 1 & 3 & 0 & 2 & 2 & 3 & 215 \\
\hline 1 & 2 & 1 & 0 & 3 & 1 & 1 & 113 \\
1 & 2 & 2 & 0 & 3 & 1 & 2 & 121 \\
1 & 2 & 3 & 0 & 3 & 1 & 3 & 132 \\
\hline 2 & 1 & 1 & 185 & 3 & 2 & 1 & 113 \\
2 & 1 & 2 & 196 & 3 & 2 & 2 & 120 \\
2 & 1 & 3 & 215 & 3 & 2 & 3 & 132 \\
\hline
\end{tabular}

TABLE 6

Electricity Sales for EMEM: with CE

\begin{tabular}{cc||c}
\hline \multicolumn{3}{c}{ Electricity demand } \\
\hline$i$ & $t$ & CE[Megawatts] \\
\hline 1 & 1 & 298 \\
1 & 2 & 316 \\
1 & 3 & 348 \\
2 & 1 & 298 \\
2 & 2 & 316 \\
2 & 3 & 348 \\
\hline
\end{tabular}

TABLE 7

Electricity demand for EMEM: with CE

their fullest capacities i.e. $m_{1}$ produces 100,000 [short ton /t] and $m_{2}$ produces 120,000 [short ton /t], as discussed previously. Table 7 shows elastic demand [Megawatts] for electricity consumer nodes $i_{1}$ and $i_{2}$ at time periods $t_{1}, t_{2}$ and $t_{3}$.

The total amount of electricity generated by both firms $f_{1}$ and $f_{2}$ at a given time $t$ is equally distributed among consumer nodes $i$ (since consumer nodes are all identical).

Table 8 shows results for shadow price of electricity $p_{i t}^{e} \mathrm{CE}(\$ / \mathrm{MWh})$. It can be seen that the price of electricity for consumer node $i_{1}$ at time $t_{1}$ is $\$ 30.13 / \mathrm{MWh}$ and for consumer node $i_{2}$ at $t_{1}$ is also $\$ 30.13 / \mathrm{MWh}$. This is because both the consumer nodes are served with same amount of electricity at given time period as discussed earlier. The price of electricity at time period $t_{3}$ is least when compared to other time periods because there is more supply of electricity during time $t_{3}$ (supply of electricity at $t_{3}>t_{2}>t_{1}$ and so is the price). Table 9 shows results for shadow 


\begin{tabular}{cc|c}
\hline \multicolumn{3}{c}{ Electricity price } \\
\hline$i$ & $t$ & $p_{i t}^{e} \mathrm{CE}(\$ / \mathrm{MWh})$ \\
\hline 1 & 1 & 30.13 \\
1 & 2 & 28.32 \\
1 & 3 & 25.15 \\
2 & 1 & 30.13 \\
2 & 2 & 28.32 \\
2 & 3 & 25.12 \\
\hline
\end{tabular}

TABLE 8

Electricity price for EMEM: with CE

\begin{tabular}{cc|c}
\hline \multicolumn{3}{c}{ Coal price } \\
\hline$v$ & $t$ & $p_{v t}^{c} \mathrm{CE}(\$ /$ Shortton $)$ \\
\hline 1 & 1 & 62.02 \\
1 & 2 & 58.12 \\
1 & 3 & 51.28 \\
2 & 1 & 41.96 \\
2 & 2 & 39.08 \\
2 & 3 & 34.04 \\
\hline
\end{tabular}

TABLE 9

Coal price for EMEM: with CE

price of coal as $p_{v t}^{c} \mathrm{CE}(\$ /$ Shortton $)$. The shadow prices of coal for coal mine region $v_{1}$ at all times is greater than shadow prices of coal mine region $v_{2}$. Recall from Figure 2 that coal producer $m_{1}$ belongs to region $v_{2}$ with a maximum capacity of 100,000(Shortton/t) and coal producer $m_{2}$ belongs to region $v_{1}$ with a maximum capacity of 120,000 (Shortton/t). In other words, region with less capacity $\left(v_{1}\right)$ has greater shadow price for coal when compared to region with more capacity. In this numerical example it varies with times $t_{1}, t_{2}$ and $t_{3}$ for region $v_{1}$ such as $\$ 62.02 /$ Shortton, $\$ 58.12 /$ Shortton and $\$ 51.28 /$ Shorton respectively because of different number of hours during each time-period. Similar explanation holds for shadow price of coal for coal mine region $v_{2}$. 


\subsection{Results for Energy Market Equilibrium Model (EMEM) with Natural Gas}

Figure 3 shows the schematic diagram of all the players involved when natural gas market is added to the existing model in Figure 2 . Natural gas players added to the baseline model are: two natural gas producers $w_{1}, w_{2}$ (identical), two pipelines $l_{1}, l_{2}$, two marketers $a_{1}, a_{2}$ (identical) and two consumer nodes $j_{1}, j_{2}$ are added to the previous model. The results of this extended model are discussed in this section.

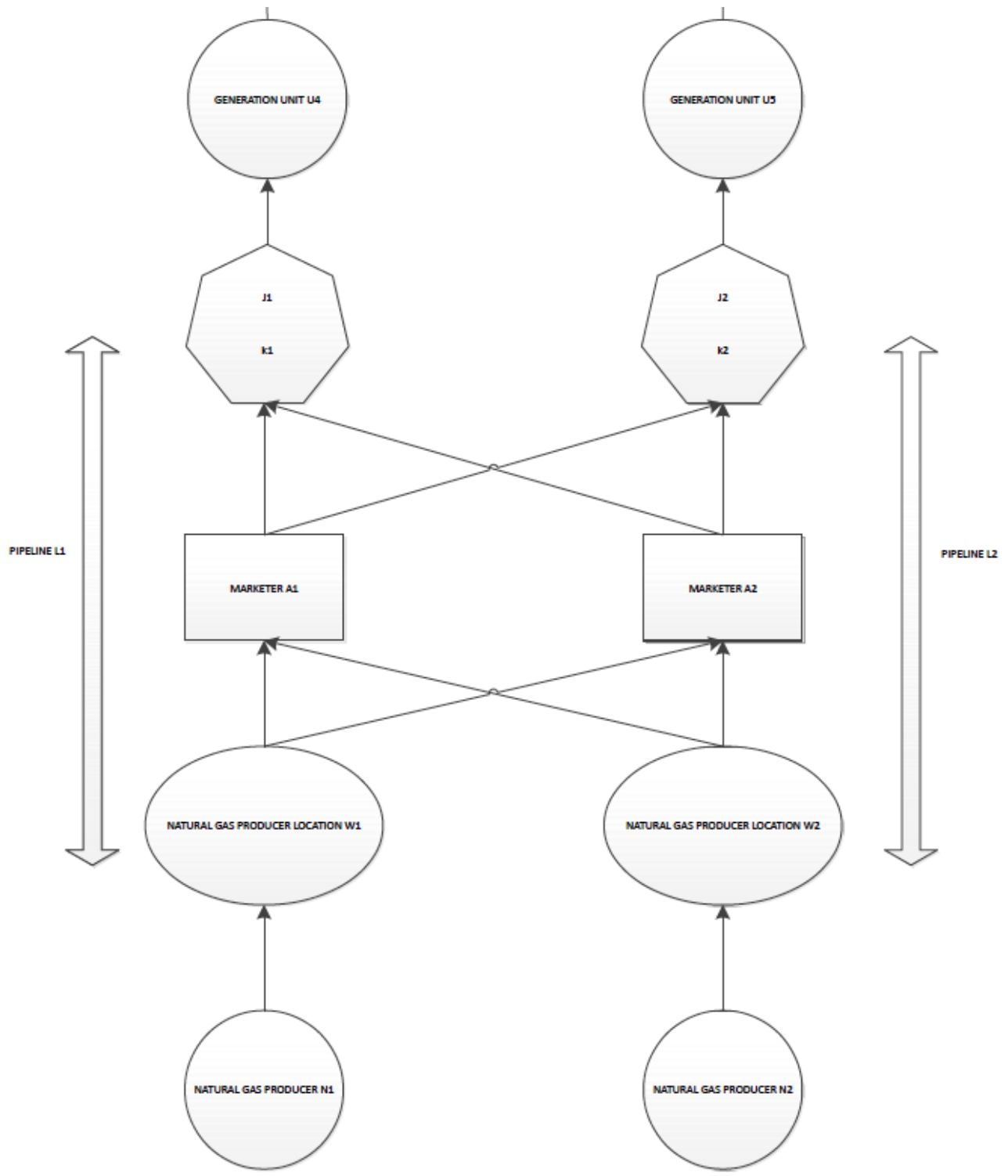

Figure 3. Electricity Market for EMEM: CNE

Before further examining the computational results, note that suffix "CE" 
means equilibrium model with coal and electricity while "CNE" means equilibrium model with coal, natural gas and electricity. The equilibrium model has used all the available capacity of coal for each of the coal producers, i.e. coal produced by coal producer $m_{1}$ is 100,0000 shortton/t at all the times and coal produced by coal producer $m_{2}$ is 120,0000 shortton/t at all times. Note that the additional natural gas fired units only causes total electricity demand to increase, but doesn't cause less coal consumption. The elastic demand for electricity nodes $i_{1}$ and $i_{2}$ is shown on Table 10. It can be seen that there is an increase in elastic demand after the introduction of natural gas into the equilibrium model. An increase of 13.69 Megawatts of electricity demand can be observed (generation unit $u_{4}$ produces 8.38 Megawatts and generation unit $u_{5}$ produces 5.31 Megawatts).

\begin{tabular}{cc|c|c}
\hline \multicolumn{4}{c}{ Electricity demand } \\
\hline$i$ & $t$ & CE[Megawatts] & CNE[Megawatts] \\
\hline 1 & 1 & 298 & 311.69 \\
1 & 2 & 316 & 329.69 \\
1 & 3 & 348 & 361.69 \\
2 & 1 & 298 & 311.69 \\
2 & 2 & 316 & 329.69 \\
2 & 3 & 348 & 361.69 \\
\hline
\end{tabular}

TABLE 10

Electricity demand for EMEM: CNE

Table 11 displays the results for sales of electricity by generation unit $u$ to demand node $i$ during time $t$. As shown in the Table 11, there are electricity sales from generation units $u_{4}$ and $u_{5}$ since they are natural gas fired units. Also sales from generation unit $u_{4}$ is greater than unit $u_{5}$. The efficiency of natural gas fired unit depends on heat rate of the respective generation unit. Here, heat rate of NG fired unit $u_{4}$ is 7.0 (MMBTU/MWh) and for $u_{5}$, it is 7.5 (MMBTU/MWh). In this case, unit $u_{5}$ is more efficient than unit $u_{4}$ but still produces less amount of electricity because of the fact that natural gas supplied to unit $u_{4}$ is greater than unit $u_{5}\left(2,740 \mathrm{MCF} /\right.$ day for generation unit $u_{4}$ and 1,860 MCF/day for generation units $u_{5}$ ). It can be observed from Table 11 that sales of electricity by generations units $u_{2}$ and $u_{3}$ are different during various time periods. This is because, electricity 
fired units depend on number of hours in that time period and coal received by the generation unit (Number of hours are set as different during each time period, $u_{4}$ receives 120,0000 shortton/t and $u_{5}$ receives 100,0000 shortton/t).

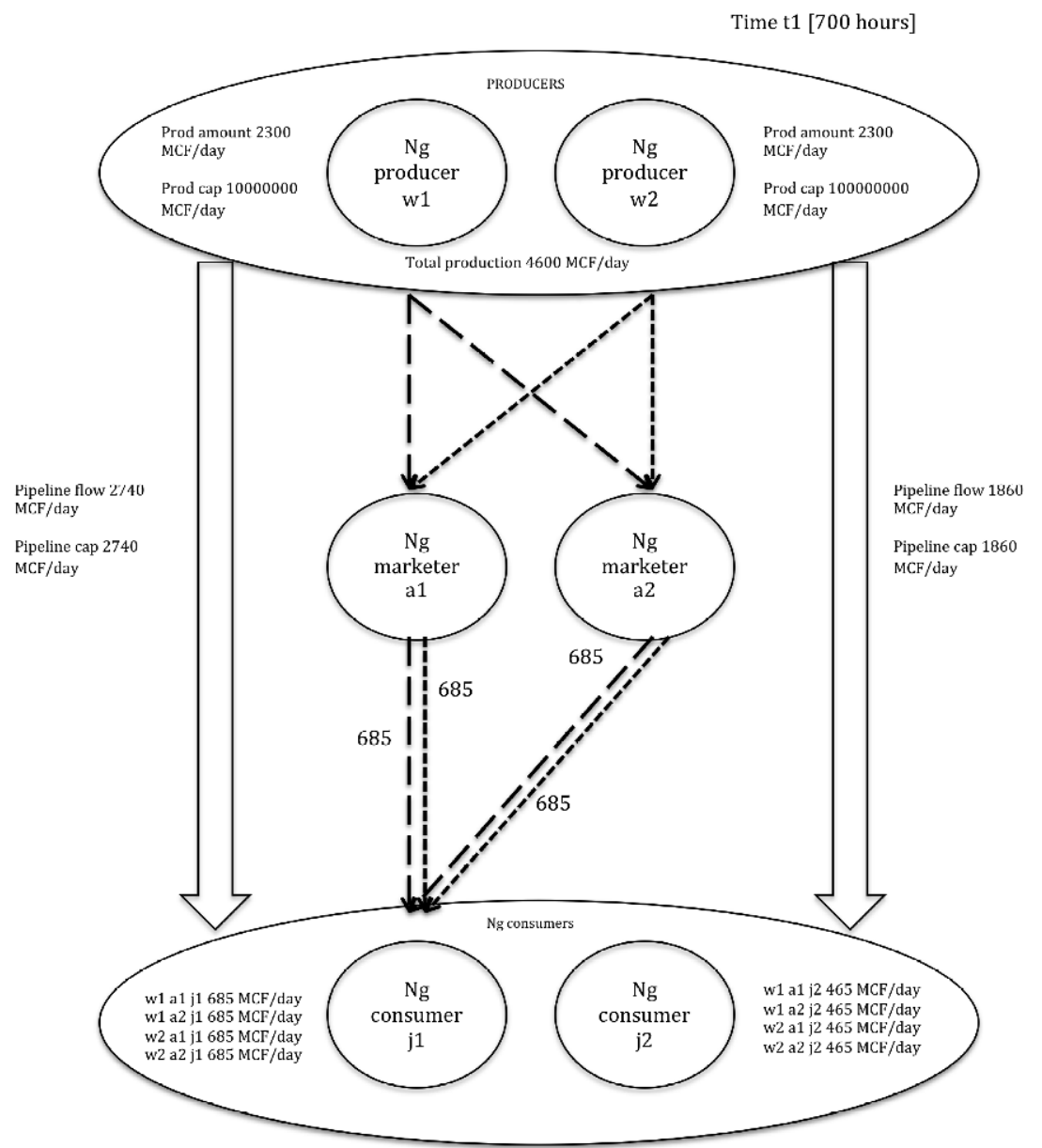

Figure 4. Flow of natural gas from producers to electric sector

Figure 4 shows natural gas flow from upstream (natural gas producers) to downstream (natural gas consumers) via midstream (natural gas pipelines). There are two identical natural gas producers considered in the model, thus both of them produce 2,300 MCF/day at all times. Also, the capacity of pipelines is fully utilized. Flow of natural gas through pipeline $l_{1}$ is $2,740 \mathrm{MCF} /$ day and through pipeline $l_{2}$ is $1,860 \mathrm{MCF} /$ day. It has to be noted that the flow of natural gas that leads to consumer $j_{1}$ is considered as pipeline $l_{1}$ and the pipeline that leads to consumer $j_{2}$ is considered as pipeline $l_{2}$. The amount of natural gas consumed by consumer $j_{1}$ is 
$685 \mathrm{MCF} /$ day at all times and the amount of natural gas consumed by consumer $j_{2}$ is $465 \mathrm{MCF} /$ day at all times. This is governed by pipelines and their capacities that connect consumers (685 times $4=2,740(\mathrm{MCF} /$ day) which is the pipeline capacity of $l=1$ and 465 times $4=1,860$ (MCF/day) which is the pipeline capacity of $l=1$ ). This shows that the numerical results exactly match with the pipeline capacities and accept flow principle.

\begin{tabular}{ccc|c|c||ccc|c|c}
\hline \multicolumn{7}{c}{ Electricity Sales } \\
\hline$u$ & $i$ & $t$ & $s_{u i t} \mathrm{CE}(\mathrm{MW})$ & $s_{\text {uit }} \mathrm{CNE}(\mathrm{MW})$ & $u$ & $i$ & $t$ & $s_{\text {uit }} \mathrm{CE}(\mathrm{MW})$ & $s_{\text {uit }} \mathrm{CNE}(\mathrm{MW})$ \\
\hline 1 & 1 & 1 & 0 & 0 & 3 & 2 & 1 & 113 & 113 \\
1 & 1 & 2 & 0 & 0 & 3 & 2 & 2 & 120 & 120 \\
1 & 1 & 3 & 0 & 0 & 3 & 2 & 3 & 132 & 132 \\
\hline 1 & 2 & 1 & 0 & 0 & 4 & 1 & 1 & 0 & 8.38 \\
1 & 2 & 2 & 0 & 0 & 4 & 1 & 2 & 0 & 8.38 \\
1 & 2 & 3 & 0 & 0 & 4 & 1 & 3 & 0 & 8.38 \\
\hline 2 & 1 & 1 & 185 & 185 & 4 & 2 & 3 & 0 & 8.38 \\
2 & 1 & 2 & 196 & 196 & 4 & 2 & 3 & 0 & 8.38 \\
2 & 1 & 3 & 215 & 215 & 4 & 2 & 3 & 0 & 8.38 \\
\hline 2 & 2 & 1 & 185 & 185 & 5 & 1 & 1 & 0 & 5.31 \\
2 & 2 & 2 & 196 & 196 & 5 & 1 & 2 & 0 & 5.31 \\
2 & 2 & 3 & 215 & 215 & 5 & 1 & 3 & 0 & 5.31 \\
\hline 3 & 1 & 1 & 113 & 113 & 5 & 2 & 1 & 0 & 5.31 \\
3 & 1 & 2 & 120 & 120 & 5 & 2 & 2 & 0 & 5.31 \\
3 & 1 & 3 & 132 & 132 & 5 & 2 & 3 & 0 & 5.31 \\
\hline
\end{tabular}

TABLE 11

Electricity sales for EMEM: CNE

Tables 12 and 13 display the results of shadow or dual prices of coal and electricity respectively. Table 12 shows the price of electricity at equilibrium with and without the addition of natural gas to the model. It can be seen that the price of electricity is less when compared to the equilibrium model without natural gas. This is because more electricity is produced than previous model due to the presence of natural gas. In both cases, the price of electricity falls in the range of [35,40] as reported by EIA 2009 [12]. Similarly, table 13 compares the price of coal between the two models. Once again, the range of $[38,40]$ is consistent with those reported by EIA 2009 [12].

Table 14 shows the upstream (natural gas producer), midstream (pipeline owner) and downstream (natural gas consumer) prices. The production price of 


\begin{tabular}{cc|c||c}
\hline \multicolumn{4}{c}{ Electricity price } \\
\hline$i$ & $t$ & $p_{i t}^{e} \mathrm{CE}(\$ / \mathrm{MWh})$ & $p_{i t}^{e} \mathrm{CNE}(\$ / \mathrm{MWh})$ \\
\hline 1 & 1 & 30.13 & 28.76 \\
1 & 2 & 28.32 & 26.95 \\
1 & 3 & 25.15 & 23.78 \\
2 & 1 & 30.13 & 28.76 \\
2 & 2 & 28.32 & 26.95 \\
2 & 3 & 25.12 & 23.78 \\
\hline
\end{tabular}

TABLE 12

Electricity price for EMEM: CNE

natural gas is considerably very less due to enormous amount of natural gas production capacity (Natural gas capacity of both the producers is 100,000000 $\mathrm{MCF} /$ day). It can also be seen that the shadow price of natural gas transportation cost and is fairly high (almost $\$ 4 / \mathrm{MCF}$ at all time periods) when compared to natural gas production price because production is governed by natural gas pipeline capacity in this equilibrium model. Also, the natural gas pipeline capacity is fully utilized. The downstream natural gas price is the sum of natural gas production price and natural gas transportation price at respective time periods $(0.019+4.09$ $=\$ 4.10 / \mathrm{MCF})$. Interestingly, the range of $[2.5,5.0]$ is consistent with those reported by EIA 2009 [12].

\begin{tabular}{cc|c|c}
\hline \multicolumn{4}{c}{ Coal price } \\
\hline$v$ & $t$ & $p_{v t}^{c} \mathrm{CE}(\$ /$ Shortton $)$ & $p_{v t}^{c} \mathrm{CNE}(\$ /$ Shortton $)$ \\
\hline 1 & 1 & 62.02 & 59.07 \\
1 & 2 & 58.12 & 55.16 \\
1 & 3 & 51.28 & 48.32 \\
2 & 1 & 41.96 & 39.78 \\
2 & 2 & 39.08 & 36.90 \\
2 & 3 & 34.04 & 21.86 \\
\hline
\end{tabular}

TABLE 13

Coal price for EMEM: CNE 


\begin{tabular}{cc|c|c||c}
\hline \multicolumn{2}{c|}{ NG Region } & \multicolumn{2}{c|}{ NG upstream price } & \multicolumn{2}{c|}{ NG midstream price } & NG downstream price \\
\hline$w$ & $t$ & $p_{w t} \mathrm{CNE}(\$ / \mathrm{MCF})$ & $p_{l t} \mathrm{CNE}(\$ / \mathrm{MCF})$ & $p_{w t} \mathrm{CNE}(\$ / \mathrm{MCF})$ \\
\hline 1 & 1 & 0.019 & 4.09 & 4.1 \\
1 & 2 & 0.019 & 3.83 & 3.85 \\
1 & 3 & 0.019 & 3.37 & 3.39 \\
2 & 1 & 0.019 & 3.81 & 3.83 \\
2 & 2 & 0.019 & 3.57 & 3.59 \\
2 & 3 & 0.019 & 3.15 & 3.17 \\
\hline
\end{tabular}

TABLE 14

Natural gas prices for EMEM: CNE

\subsection{Results for EMEM with non-electricity natural gas usage}

The model discussed in this section is different from the one that has been discussed in previous section 4.5 due to the presence of non-electric sector that consumes natural gas. In addition to two natural gas producers $w_{1}, w_{2}$ (identical), two pipelines $l_{1}, l_{2}$, two marketers $a_{1}, a_{2}$ (identical) and two consumer nodes $j_{1}, j_{2}$, now there are two sectors added to the model $k_{1}, k_{2}$ where sector $k_{1}$ belongs to electric sector (meaning - natural gas that is supplied to sector $k_{1}$ is exclusively used for the production of electricity), sector $k_{2}$ belongs to non-electric sector (e.g., consumers and businesses who use natural gas for heating). Figure 5 shows the schematic representation of all the players with their interactions. We have conducted preliminary testing for this framework using GAMS/PATH, which is not discussed in this thesis.

Like previous section, "CE" refers to the results of model in section 4.c.1, "CNE" refers to the results of model in Section 4.5 and "CNE-NonE" which means coal, natural gas, electricity and non electric sector for natural gas refers to the results of model in this section. Here, the results of all the three models are compared with each other.

Table 15 displays the results for sales of electricity by generation unit $u$ to demand node $i$ during time $t$. As shown in the Table 15, there are electricity sales from generation units $u_{2}, u_{3}, u_{4}$ and $u_{5}$. The sales from generation unit $u_{4}$ and generation unit $u_{5}$ are dropped (from 8.38 MW to $2.54 \mathrm{MW}$ for unit 4 and $5.31 \mathrm{MW}$ 


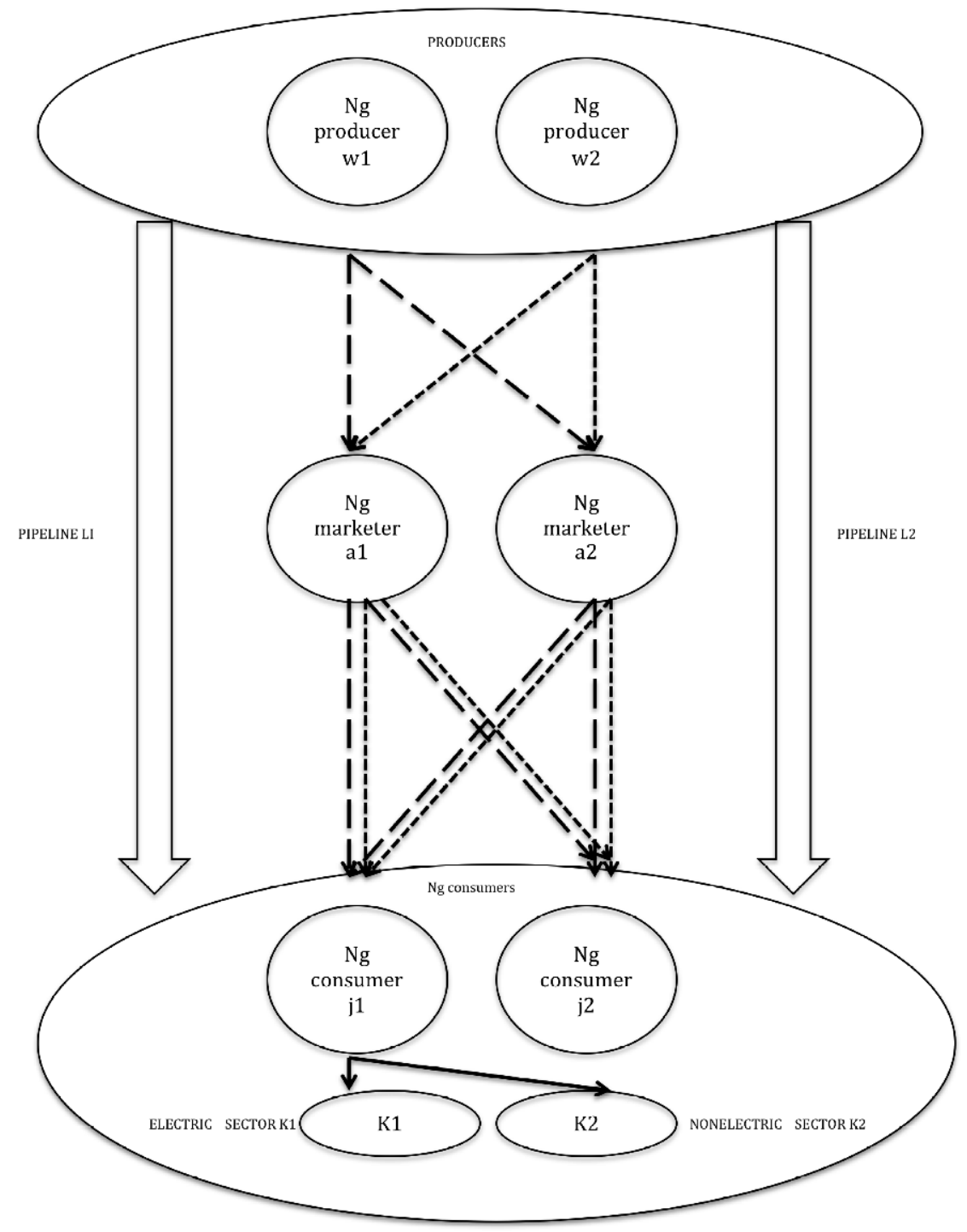

Figure 5. Natural gas market after the introduction of NonE sector

to $1.60 \mathrm{MW}$ ) in this case due to the addition of non-electric sector within natural gas market. The quantity of natural gas that has to be supplied to non-electric sector is governed by an additional constraint added in this model. This constraint says that almost $70 \%$ of the total natural gas produced must be supplied to non-electric sector. As a result, the amount of electricity generated by units $u_{4}$ and $u_{5}$ is less than previous model and can be between two columns headed as $s_{\text {uit }} \mathrm{CNE}(\mathrm{MW})$ and $s_{\text {uit }} \mathrm{CNE}-\mathrm{NonE}(\mathrm{MW})$.

Like previous model described in Section 4.5, this equilibrium model has also used all the available capacity of coal for each of the coal producers i.e. coal 
produced by coal producer $m_{1}$ is 100,0000 shortton/t at all the times and coal produced by coal producer $m_{2}$ is 120,0000 shortton/t at all times. Note that the additional non-electric sector doesn't cause less coal consumption but only produces less electricity.

\begin{tabular}{ccc|c|c|c||ccc|c|c|c}
\hline \multicolumn{10}{c}{ Electricity Sales (MW) } \\
\hline$u$ & $i$ & $t$ & $s_{u i t} \mathrm{CE}$ & $s_{\text {uit }} \mathrm{CNE}$ & $s_{\text {uit }}$ CNE-NonE & $u$ & $i$ & $t$ & $s_{u i t} \mathrm{CE}$ & $s_{u i t} \mathrm{CNE}$ & $s_{\text {uit }}$ CNE-NonE \\
\hline 1 & 1 & 1 & 0 & 0 & 0 & 3 & 2 & 1 & 113 & 113 & 113 \\
1 & 1 & 2 & 0 & 0 & 0 & 3 & 2 & 2 & 120 & 120 & 120 \\
1 & 1 & 3 & 0 & 0 & 0 & 3 & 2 & 3 & 132 & 132 & 132 \\
\hline 1 & 2 & 1 & 0 & 0 & 0 & 4 & 1 & 1 & 0 & 8.38 & 2.54 \\
1 & 2 & 2 & 0 & 0 & 0 & 4 & 1 & 2 & 0 & 8.38 & 2.54 \\
1 & 2 & 3 & 0 & 0 & 0 & 4 & 1 & 3 & 0 & 8.38 & 2.54 \\
\hline 2 & 1 & 1 & 185 & 185 & 185 & 4 & 2 & 3 & 0 & 8.38 & 2.54 \\
2 & 1 & 2 & 196 & 196 & 196 & 4 & 2 & 3 & 0 & 8.38 & 2.54 \\
2 & 1 & 3 & 215 & 215 & 215 & 4 & 2 & 3 & 0 & 8.38 & 2.54 \\
\hline 2 & 2 & 1 & 185 & 185 & 185 & 5 & 1 & 1 & 0 & 5.31 & 1.60 \\
2 & 2 & 2 & 196 & 196 & 196 & 5 & 1 & 2 & 0 & 5.31 & 1.60 \\
2 & 2 & 3 & 215 & 215 & 215 & 5 & 1 & 3 & 0 & 5.31 & 1.60 \\
\hline 3 & 1 & 1 & 113 & 113 & 113 & 5 & 2 & 1 & 0 & 5.31 & 1.60 \\
3 & 1 & 2 & 120 & 120 & 120 & 5 & 2 & 2 & 0 & 5.31 & 1.60 \\
3 & 1 & 3 & 132 & 132 & 132 & 5 & 2 & 3 & 0 & 5.31 & 1.60 \\
\hline
\end{tabular}

TABLE 15

Electricity sales for EMEM: CNE-NonE

\begin{tabular}{cc|c||c||c}
\hline \multicolumn{4}{c}{ Electricity demand (MW) } \\
\hline$i$ & $t$ & CE[Megawatts] & CNE[Megawatts] & CNE-NonE[Megawatts] \\
\hline 1 & 1 & 298 & 311.69 & 302.85 \\
1 & 2 & 316 & 329.69 & 320.95 \\
1 & 3 & 348 & 361.69 & 352.63 \\
2 & 1 & 298 & 311.69 & 302.85 \\
2 & 2 & 316 & 329.69 & 320.95 \\
2 & 3 & 348 & 361.69 & 352.63 \\
\hline
\end{tabular}

TABLE 16

Electricity demand for EMEM: CNE-NonE

The elastic demand for electricity nodes $i_{1}$ and $i_{2}$ is shown on Table 17 . It can be seen that there is decrease in elastic demand after the introduction of non-electric sector for consumption of natural gas into the equilibrium model. Decrease of around 10 Megawatts of electricity demand can be observed for 


\begin{tabular}{cc|c||c||c}
\hline \multicolumn{5}{c}{ Electricity price } \\
\hline$i$ & $t$ & $p_{i t}^{e} \mathrm{CE}(\$ / \mathrm{MWh})$ & $p_{i t}^{e} \mathrm{CNE}(\$ / \mathrm{MWh})$ & $p_{i t}^{e} \mathrm{CNE}-\mathrm{NonE}(\$ / \mathrm{MWh})$ \\
\hline 1 & 1 & 30.13 & 28.76 & 29.71 \\
1 & 2 & 28.32 & 26.95 & 27.9 \\
1 & 3 & 25.15 & 23.78 & 24.73 \\
2 & 1 & 30.13 & 28.76 & 29.71 \\
2 & 2 & 28.32 & 26.95 & 27.90 \\
2 & 3 & 25.12 & 23.78 & 24.73 \\
\hline
\end{tabular}

TABLE 17

Electricity price for EMEM: CNE-NonE

\begin{tabular}{cc|c||c||c}
\hline \multicolumn{5}{c}{ Coal price } \\
\hline$v$ & $t$ & $p_{v t}^{c}$ CE $(\$ /$ Shortton $)$ & $p_{v t}^{c}$ CNE $(\$ /$ Shortton $)$ & $p_{v t}^{c}$ CNE-NonE $(\$ /$ Shortton $)$ \\
\hline 1 & 1 & 62.02 & 59.07 & 61.13 \\
1 & 2 & 58.12 & 55.16 & 57.22 \\
1 & 3 & 51.28 & 48.32 & 50.38 \\
2 & 1 & 41.96 & 39.78 & 41.30 \\
2 & 2 & 39.08 & 36.90 & 38.42 \\
2 & 3 & 34.04 & 21.86 & 33.37 \\
\hline
\end{tabular}

TABLE 18

Coal price for EMEM: CNE-NonE

electricity demand node $i_{1}$ at time $t_{1}$ (generation unit $u_{4}$ produces 2.54 Megawatts (8.38 Megawatts earlier) and generation unit $u_{5}$ produces 1.60 Megawatts (5.31 Megawatts earlier). This decrease in production of electricity due to consumption of natural gas by non-electric sector is reflected in elastic demand.

Figure 6 shows natural gas flow from upstream (natural gas producers) to downstream (natural gas consumers) via midstream (natural gas pipelines). There

\begin{tabular}{c||c|c|c||c|c|c}
\hline Time & \multicolumn{2}{|c|}{ W/O Non-Electric Sector } & \multicolumn{3}{c}{ With Non-Electric Sector } \\
\hline$t$ & $w$ & $p_{w t} \mathrm{CNE}(\$ / \mathrm{MCF})$ & $p_{w t} \mathrm{CNE}-$ NonE $(\$ / \mathrm{MCF})$ & $l$ & $p_{l t} \mathrm{CNE}(\$ / \mathrm{MCF})$ & $p_{l t} \mathrm{CNE}-\mathrm{NonE}(\$ / \mathrm{MCF})$ \\
\hline 1 & 1 & 0.019 & 0.019 & 1 & 4.09 & 4.22 \\
2 & 1 & 0.019 & 0.019 & 1 & 3.83 & 3.96 \\
3 & 1 & 0.019 & 0.019 & 1 & 3.37 & 3.51 \\
1 & 2 & 0.019 & 0.019 & 2 & 3.81 & 3.94 \\
2 & 2 & 0.019 & 0.019 & 2 & 3.57 & 3.70 \\
3 & 2 & 0.019 & 0.019 & 3.15 & 3.27 \\
\hline
\end{tabular}

TABLE 19

Natural gas upstream and midstream prices for EMEM: CNE-NonE 


\begin{tabular}{ccc||c|c}
\hline & & & W/O Non-Electric Sector & With Non-Electric Sector \\
\hline$j$ & $k$ & $t$ & $p_{j k t}$ CNE $(\$ / \mathrm{MCF})$ & $p_{j k t}$ CNE-NonE $(\$ / \mathrm{MCF})$ \\
\hline 1 & 1 & 1 & 4.1 & 4.24 \\
1 & 1 & 2 & 3.85 & 3.98 \\
1 & 1 & 3 & 3.39 & 3.53 \\
1 & 2 & 1 & 0 & 4.24 \\
1 & 2 & 2 & 0 & 3.98 \\
1 & 2 & 3 & 0 & 3.53 \\
2 & 1 & 1 & 3.83 & 3.96 \\
2 & 1 & 2 & 3.59 & 3.72 \\
2 & 1 & 3 & 3.17 & 3.29 \\
2 & 2 & 1 & 0 & 3.96 \\
2 & 2 & 2 & 0 & 3.72 \\
2 & 2 & 3 & 0 & 3.29 \\
\hline
\end{tabular}

TABLE 20

Natural gas downstream prices for EMEM: CNE-NonE

are two identical natural gas producers considered in the model and can be seen that both of them produce 2,300 MCF/day at all times. Also, the capacity of pipelines is fully utilized. Flow of natural gas through pipeline $l_{1}$ is $2,740 \mathrm{MCF} /$ day and through pipeline $l_{2}$ is $1,860 \mathrm{MCF} /$ day. Similar to previous Section 4.5, it has to be noted that the flow of natural gas that leads to consumer $j_{1}$ is considered as pipeline $l_{1}$ and the pipeline that leads to consumer $j_{2}$ is considered as pipeline $l_{2}$. The amount of natural gas consumed by consumer $j_{1}$ is $685 \mathrm{MCF} /$ day at all times and the amount of natural gas consumed by consumer $j_{2}$ is $465 \mathrm{MCF} /$ day at all times. This is governed by pipelines and their capacities that connect consumers $\left(685 \times 4=2740(\mathrm{MCF} /\right.$ day $)$ which is the pipeline capacity of $l_{1}$ and $465 \times 4=1860$ $\left(\mathrm{MCF} /\right.$ day) which is the pipeline capacity of $\left.l_{1}\right)$. This shows that the numerical results exactly match with the pipeline capacities and accept flow principle. As there are two sectors introduced - $k_{1}$ electric and $k_{2}$ non-electric, amount 5 of natural gas received by consumer nodes $j_{1}$ and $j_{2}$ are distributed between $k_{1}$ and $k_{2}$. This distribution is governed by a constraint that says almost $70 \%$ of natural gas has to be sent to non-electric sector. Hence, amount of natural gas received by electric sector $k_{1}$ via natural gas consumer node $j_{1}$ at time $t_{1}$ is 207.5 (MCF/day) instead of $685 \mathrm{MCF} /$ day. Remaining amount of natural gas is sent to non-electric sector $k_{2}$, 
i.e. 477.5(MCF/day). Figure 6 and Table 21 show the distribution of natural gas natural gas producer $w$ to market $a$ to consumer node $j$ to sector $k$ in time $t$. Note that Figure 6 shows values only for $w_{1}, a_{1}, j_{1}, k_{1}$ and $w_{1}, a_{1}, j_{1}, k_{2}$ at time $t_{1}$. Also Table 21 shows values for marketer $a_{1}$, marketer $a_{2}$ is ignored as both the marketers are identical and have exactly the same values.

\begin{tabular}{|c|c|c|c|c|c|c|c|c|c|c|c|c|c|}
\hline & & & & & $\mathrm{W} / \mathrm{O} \mathrm{NE}$ & With Non-Electric & & & & & & $\mathrm{W} / \mathrm{O} \mathrm{NE}$ & With Non-Electric \\
\hline$a$ & $w$ & $j$ & $k$ & $t$ & $q_{a w j k t} \mathrm{CNE}$ & $q_{a w j k t} \mathrm{CNE}$ with NE & $a$ & $w$ & $j$ & $k$ & $t$ & $q_{a w j k t} \mathrm{CNE}$ & $q_{a w j k t} \mathrm{CNE}$ with NE \\
\hline 1 & 1 & 1 & 1 & 1 & 685 & 207 & 1 & 2 & 1 & 1 & 1 & 685 & 207 \\
\hline 1 & 1 & 1 & 1 & 2 & 685 & 207 & 1 & 2 & 1 & 1 & 2 & 685 & 207 \\
\hline 1 & 1 & 1 & 1 & 3 & 685 & 207 & 1 & 2 & 1 & 1 & 3 & 685 & 207 \\
\hline 1 & 1 & 1 & 2 & 1 & 0 & 477 & 1 & 2 & 1 & 2 & 1 & 0 & 477 \\
\hline 1 & 1 & 1 & 2 & 2 & 0 & 477 & 1 & 2 & 1 & 2 & 2 & 0 & 477 \\
\hline 1 & 1 & 1 & 2 & 3 & 0 & 477 & 1 & 2 & 1 & 2 & 3 & 0 & 477 \\
\hline 1 & 1 & 2 & 1 & 1 & 465 & 140 & 1 & 2 & 2 & 1 & 1 & 465 & 140 \\
\hline 1 & 1 & 2 & 1 & 2 & 465 & 140 & 1 & 2 & 2 & 1 & 2 & 465 & 140 \\
\hline 1 & 1 & 2 & 1 & 3 & 465 & 140 & 1 & 2 & 2 & 1 & 3 & 465 & 140 \\
\hline 1 & 1 & 2 & 2 & 1 & 0 & 324 & 1 & 2 & 2 & 2 & 1 & 0 & 324 \\
\hline 1 & 1 & 2 & 2 & 2 & 0 & 324 & 1 & 2 & 2 & 2 & 2 & 0 & 324 \\
\hline 1 & 1 & 2 & 2 & 3 & 0 & 324 & 1 & 2 & 2 & 2 & 3 & 0 & 324 \\
\hline
\end{tabular}

TABLE 21

Natural gas sales by marketer for EMEM: CNE-NonE

Tables 17 and 18 display the results of shadow or dual prices of electricity and coal respectively. Table 18 compares the price of coal at equilibrium with and without the addition of non-electric sector to the model. It can be seen that the price of coal is greater $\left(\$ 61.13 /\right.$ shortton for $v_{1}$ at $\left.t_{1}\right)$ when compared to the equilibrium model without non-electric sector $\left(\$ 59.07 /\right.$ shortton) for $v_{1}$ at $\left.t_{1}\right)$ but less than the model that has only coal and electricity at equilibrium $(\$ 62.02 /$ shortton $)$ for $v_{1}$ at $\left.t_{1}\right)$. This is because shadow price directly depends on amount of electricity demand that is being fulfilled. For example, Table 16 shows that the CE scenario yields the least electricity demand for consumer node $i_{1}$ at time $t_{1} 298 \mathrm{MW}$, followed by $302 \mathrm{MW}$ in the CNE-NonE scenario and then by $312 \mathrm{MW}$ in the CNE scenario. This is perfectly aligned with the order of the shadow price of coal, which is $\$ 59.07 /$ shortton in the CNE scenario followed by $\$ 61.13 /$ shortton in the CNE-NonE scenario and then by $\$ 62.02 /$ shortton in the CE scenario. In all the three cases, the price of coal is close to the range of [38,40] as reported by EIA 2009 [12]. Similarly, table 17 compares the price of electricity between the three models and it can be 
seen that for consumer node $i_{1}$ at time $t_{1}$ the price is $\$ 30.13 / \mathrm{MWh}$ in CE scenario followed by $\$ 28.76 / \mathrm{MWh}$ in the CNE scenario and $\$ 29.71 / \mathrm{MWh}$ in the CNE-NonE scenario.It follows exactly same reasons as described for coal shadow price. Once again, the range of $[35,40]$ is consistent with those reported by EIA 2009 [12].

Table 19 shows the upstream (natural gas producer) and midstream (pipeline owner). The production price of natural gas doesn't change when compared to previous model i.e. $0.0019(\$ / \mathrm{MWh}))$ due to enormous amount of natural gas production capacity (Natural gas capacity of both the producers is 100,000000 $\mathrm{MCF} /$ day). Table 20 shows the downstream price (natural gas marketer) of natural gas at which marketer $a$ sells to consumer node $j$ for sect $k$ during time $t$. This price slightly increases $\left(\$ 4.224 / \mathrm{MCF}\right.$ at $\left.j_{1}, k_{1}, t_{1}\right)$ when compared to previous model $\left(\$ 4.1 / \mathrm{MCF}\right.$ at $\left.j_{1}, k_{1}, t_{1}\right)$ without non-electric sector because of change in amount of natural gas that is being sent to non-electric sector. Interestingly, the range of $[2.5,5.0]$ is also consistent with those reported by EIA 2009 [12] in this model with non-electric sector.

\subsection{Sensitivity analysis for EMEM}

In this section, sensitivity analysis is performed on EMEM model including natural gas market and further its non-electric users. This analysis helps in better understanding of affect of parameters on the developed model. We first vary natural gas pipeline capacity and change it form 2,740 MCF/day and 1,860 $\mathrm{MCF} /$ day to 100,00000 MCF/day for both.

Efficiency of generation units depend on their heat rate and heat content. Generation unit $u_{4}$ costs $\$ 18.45 / \mathrm{MWh}$ and generation unit $u_{5}$ costs $\$ 19.77 / \mathrm{MWh}$. Since $u_{4}$ is more efficient than $u_{5}$, natural gas is sent to unit $u_{4}$. This results in the production of electricity and sales by unit $u_{4}$ as shown in Table 22 . It has to be recalled that generation units $u 1, u 2$ and $u_{4}$ belong to firm $f_{1}$ and $u 3, u 5$ belongs to

firm $f_{2}$. Unit $u_{2}$ doesn't produce electricity in this case because unit $u_{4}$ that belongs to the same firm as unit $u_{2}$ produces electricity using natural gas. Coal producer $m_{1}$ uses its full capacity and produces 100,000 shortton/t as it supplies to generation 


\begin{tabular}{ccc|c|c||ccc|c|c}
\hline \multicolumn{7}{c}{ Electricity Sales (MW) } \\
\hline$u$ & $i$ & $t$ & $s_{u i t}$ CNE-NonE & $s_{u i t}$ CNE(SA pipeline cap) & $u$ & $i$ & $t$ & $s_{u i t}$ CNE-NonE & $s_{u i t}$ CNE(SA pipeline cap) \\
\hline 1 & 1 & 1 & 0 & 0 & 3 & 2 & 1 & 113 & 113 \\
1 & 1 & 2 & 0 & 0 & 3 & 2 & 2 & 120 & 120 \\
1 & 1 & 3 & 0 & 0 & 4 & 2 & 3 & 132 & 132 \\
\hline 1 & 2 & 1 & 0 & 0 & 4 & 1 & 2.54 & 396 \\
1 & 2 & 2 & 0 & 0 & 4 & 1 & 3 & 2.54 & 390 \\
1 & 2 & 3 & 0 & 0 & 4 & 2 & 3 & 2.54 & 396 \\
\hline 2 & 1 & 1 & 185 & 0 & 2 & 3 & 2.54 & 396 \\
2 & 1 & 2 & 196 & 0 & 5 & 2 & 3 & 2.54 & 396 \\
2 & 1 & 3 & 215 & 0 & 5 & 1 & 1 & 1.60 & 0 \\
\hline 2 & 2 & 1 & 185 & 0 & 5 & 1 & 3 & 1.60 & 0 \\
2 & 2 & 2 & 196 & 0 & 5 & 2 & 1 & 1.60 & 0 \\
2 & 2 & 3 & 215 & 0 & 5 & 2 & 2 & 1.60 & 0 \\
\hline 3 & 1 & 1 & 113 & 113 & 5 & 2 & 3 & 1.60 & 0 \\
3 & 1 & 2 & 120 & 120 & & \\
3 & 1 & 3 & 132 & 132 & &
\end{tabular}

TABLE 22

Electricity sales for EMEM: Sensitivity Analysis

unit $u_{3}$. Coal producer $m_{2}$ is not allowed to produce coal as units $u_{1}$ and $u_{2}$ do not produce electricity in this case. Natural gas producers almost produce 200,000 $\mathrm{MCF}$ /day rather than 2000 - $3000 \mathrm{MCF} /$ day due to increase in pipeline capacity enormously.

\begin{tabular}{cc|c|c}
\hline \multicolumn{3}{c}{ Electricity demand } \\
\hline$i$ & $t$ & CNE-NonE[Megawatts] & CNE-NonE(SA pipeline cap) \\
\hline 1 & 1 & 302 & 509 \\
1 & 2 & 320 & 511 \\
1 & 3 & 352 & 513 \\
2 & 1 & 302 & 509 \\
2 & 2 & 320 & 511 \\
2 & 3 & 352 & 513 \\
\hline
\end{tabular}

TABLE 23

Electricity demand for EMEM: Sensitivity Analysis

Table 23 shows the increase in electricity demand after increase in pipeline capacity of natural gas. Almost $50 \%$ of electricity demand is satisfied by unit $u_{4}$ which is natural gas fired. Flow of natural gas through pipeline $l_{1}$ is around 400,000 $\mathrm{MCF} /$ day and there is no flow through pipeline $l_{2}$ as it leads to generation unit $u_{5}$ (unit $u_{5}$ doesn't produce electricity as discussed earlier).

The prices of coal and electricity becomes interesting in this sensitive 
analysis. Table 27 compares the shadow price of coal. Price of coal for coal producer $m_{2}$ is only $8.34 \$$ shortton at time $t_{1}$, which was $41.30 \$ /$ shortton. This is because of increase in use of natural gas for production of electricity. Table 25 shows the price of electricity, which is much lower at $\$ 9.009 / \mathrm{MWh}$ for $i 1, t 1$, almost one-third of the price as it was without pipeline capacity expansion $(\$ 29.71 / \mathrm{MWh}$ for $i 1, t 1)$. This is because of increase in elastic demand and excess availability of resources for production of electricity.

\begin{tabular}{cc|c||c}
\hline \multicolumn{3}{c}{ Coal price } \\
\hline$v$ & $t$ & $p_{v t}^{c}$ CNE(\$/Shortton) & $p_{v t}^{c}$ CNE (SA pipeline cap)(\$/Shortton) \\
\hline 1 & 1 & 61.13 & 52.72 \\
1 & 2 & 57.22 & 52.73 \\
1 & 3 & 50.38 & 52.59 \\
2 & 1 & 41.30 & 8.34 \\
2 & 2 & 38.4 & 8.13 \\
2 & 3 & 33.37 & 7.78 \\
\hline
\end{tabular}

TABLE 24

Coal price for for EMEM: Sensitivity Analysis

\begin{tabular}{cc|c||c}
\hline \multicolumn{3}{c}{ Electricity price } \\
\hline$i$ & $t$ & $p_{i t}^{e} \mathrm{CNE}(\$ / \mathrm{MWh})$ & $p_{i t}^{e} \mathrm{CNE}(\mathrm{SA}$ pipeline cap $)(\$ / \mathrm{MWh})$ \\
\hline 1 & 1 & 29.71 & 9.009 \\
1 & 2 & 27.90 & 8.882 \\
1 & 3 & 24.73 & 8.659 \\
2 & 1 & 29.71 & 9.009 \\
2 & 2 & 27.90 & 8.882 \\
2 & 3 & 24.73 & 8.659 \\
\hline
\end{tabular}

TABLE 25

Electricity price for EMEM: Sensitivity Analysis

Natural gas price of upstream is also one interesting thing as the production price increased from $\$ 0.019 / \mathrm{MCF}$ to almost $\$ 1.2 / \mathrm{MCF}$ because of increase in production and relatively less gap between production and available capacity. In previous model, production was 2,300 MCF/day while available capacity is $100,000000 \mathrm{MCF} /$ day. But, in this model production is almost 2,000,000 MCF/day with same available capacity. Where as, midstream price of natural gas is nearly 
zero due to enormous amount of available capacity. This resulted in natural gas downstream price to drop from $\$ 4.0 / \mathrm{MCF}$ - $\$ 5.0 / \mathrm{MCF}$ to nearly $\$ 1.2 / \mathrm{MCF}$ $\$ 1.3 / \mathrm{MCF}$.

Secondly, we vary coefficients of inverse demand function of electricity. The present function is $P_{j t}^{e}(\cdot)=c_{o}-c_{1} d_{i t}^{e}\left(c_{o}=60, c_{1}=0.1\right)$. Initially, co-efficient $c_{o}$ is increased by 40 till $c_{o}$ reaches 200 keeping $c_{1}$ constant. In all the cases, change in inverse demand function doesn't affect sales of electricity by generation unit $u$ to demand node $i$ at time $t\left(s_{\text {uit }}\right)$. Sales of electricity remain exactly the same as in Table 11. It doesn't affect the amount of coal produced either. Coal producers $m_{1}$ and $m_{2}$ continue to produce 100,000 shortton/t and 120,000 shortton/t in all cases. Also, same holds for electricity demand $d_{i t}^{e}$ and can be seen in Table 10. Flow of natural gas through pipelines $l_{1}$ and $l_{2}$ is $2,740 \mathrm{MCF} /$ day and $1,860 \mathrm{MCF} /$ day in all cases in this analysis.

Since, values of $s_{u i t}, z_{m t}, d_{i t}^{e}, g_{n t}, f_{l t}$ and $q_{a w j k t}$ do not change with change in coefficient $c_{o}$ of inverse demand function, their tables showing values are ignored. Interesting part of this sensitivity analysis lies in shadow prices of coal $\left(p_{v t}^{c}\right)$, electricity $\left(p_{i t}^{e}\right)$, natural gas pipeline $\left(p_{l t}\right)$ and natural gas marketer $\left(p g_{j k t}\right)$. Inverse demand function is a function that maps the quantity of output demanded to the market price for that output. As demand satisfied depends on availability of resources (coal and natural gas in this case), it remains unchanged. Therefore, the price of electricity directly depends on coefficient $c_{o}$.

\begin{tabular}{cc|c|c|c|c|c}
\hline \multicolumn{7}{c}{ Electricity price $p_{i t}^{e}(\$ / \mathrm{MWh})$} \\
\hline$i$ & $t$ & $c_{o}=60$ & $c_{o}=80$ & $c_{o}=120$ & $c_{o}=160$ & $c_{o}=200$ \\
\hline 1 & 1 & 28.76 & 48 & 88 & 128 & 168 \\
1 & 2 & 26.95 & 46 & 86 & 126 & 166 \\
1 & 3 & 23.78 & 43 & 83 & 123 & 163 \\
2 & 1 & 28.76 & 48 & 88 & 128 & 168 \\
2 & 2 & 26.95 & 46 & 86 & 126 & 166 \\
2 & 3 & 23.78 & 43 & 83 & 123 & 163 \\
\hline
\end{tabular}

TABLE 26

Electricity price for EMEM: different coefficients of inverse demand function $\left(c_{o}\right)$

Table 26 shows the price of electricity for node $i$ at equilibrium when 
coefficient $c_{o}$ of inverse demand function is changed. It can be seen that increase in co-efficient of $c_{o}$ results in increase of electricity price. When observed closely, electricity price for node $i_{1}$, time $t_{1}, c_{o}=120$ is $128[\$ / \mathrm{MWh}]$ and for $c_{o}=200$ is $168[\$ / M W h]$. This is just an example for one case but similar pattern can be observed in all the cases. An addition of 40 to coefficient $c_{o}$ results in an increase of $40 \$ /$ MWh of electricity price and follows a linear relationship. We'd like to investigate the theoretical aspect of this observation in a future study.

\begin{tabular}{cc|c|c|c|c|c}
\hline \multicolumn{7}{c}{ Coal price $p_{v t}^{c}$ (\$/Shortton) } \\
\hline$v$ & $t$ & $c_{o}=60$ & $c_{o}=80$ & $c_{o}=120$ & $c_{o}=160$ & $c_{o}=200$ \\
\hline 1 & 1 & 59.07 & 102 & 188 & 274 & 361 \\
1 & 2 & 55.16 & 98 & 184 & 270 & 357 \\
1 & 3 & 48.32 & 91 & 177 & 264 & 350 \\
2 & 1 & 39.78 & 71 & 135 & 198 & 262 \\
2 & 2 & 36.90 & 68 & 132 & 196 & 259 \\
2 & 3 & 21.86 & 63 & 127 & 191 & 254 \\
\hline
\end{tabular}

TABLE 27

Coal price for EMEM: different coefficients of inverse demand function $\left(c_{o}\right)$

The increase in coefficient $c_{o}$ demands for more electricity for the given price. As mentioned earlier, amount of resources are limited in this model and are not allowed to produce more electricity. Table 27 shows coal price for region $v$ at equilibrium. For region $v_{1}$, time $t_{1}$, coefficient $c_{o}=80$, coal price is $102 \$ /$ shortton and for $c_{o}=120$ it is $188 \$$ /shortton. Increase in positive coefficient results in increase in coal price due to more demand. Interestingly, coal price also follows a specific pattern i.e. an increase in 40 to coefficient $c_{o}$ results in an increase of around $86 \$ /$ shortton of coal price.

Tables 28 and 29 shows the shadow price for natural gas transportation pipelines and downstream. Increase in coefficient $c_{o}$ increase these prices. For instance, transportation price of pipeline $l_{1}$, at time $t_{1}$ for $c_{o}=80$ is $6.94[\$ / \mathrm{MCF}]$ and for $c_{o}=120$ is $12.66[\$ / \mathrm{MCF}]$. Like coal and electricity prices, natural gas transportation price also follows a pattern with increase in positive coefficient of inverse demand function. An increase in 40 to coefficient $c_{o}$ results in an increase of around 6 \$ MCF. Natural gas production price remains unchanged (0.019 \$/MCF) 


\begin{tabular}{cc|c|c|c|c|c}
\hline \multicolumn{6}{c}{ Natural gas transportation price $p_{l t}(\$ / \mathrm{MCF})$} \\
\hline$l$ & $t$ & $c_{o}=60$ & $c_{o}=80$ & $c_{o}=120$ & $c_{o}=160$ & $c_{o}=200$ \\
\hline 1 & 1 & 4.09 & 6.94 & 12.66 & 18.37 & 24.09 \\
1 & 2 & 3.83 & 6.68 & 12.4 & 18.11 & 24.83 \\
1 & 3 & 3.37 & 6.23 & 11.95 & 17.66 & 23.37 \\
2 & 1 & 3.81 & 6.48 & 11.81 & 17.44 & 22.48 \\
2 & 2 & 3.57 & 6.24 & 11.57 & 16.9 & 22.24 \\
2 & 3 & 3.15 & 5.81 & 11.15 & 16.48 & 21.81 \\
\hline
\end{tabular}

TABLE 28

Natural gas transportation rates for EMEM: different coefficients of inverse demand function $\left(c_{o}\right)$

because of its huge capacity. Natural gas downstream price is the sum of transportation price and production price. Table 29 shows that it follows similar results as in transportation price and adds 0.019 \$/MCF for each case.

\begin{tabular}{cc|c|c|c|c|c}
\hline \multicolumn{7}{c}{ Ng downstream price $p_{j t}^{g}(\$ / \mathrm{MCF})$} \\
\hline$j$ & $t$ & $c_{o}=60$ & $c_{o}=80$ & $c_{o}=120$ & $c_{o}=160$ & $c_{o}=200$ \\
\hline 1 & 1 & 4.1 & 6.96 & 12.68 & 18.39 & 24.1 \\
1 & 2 & 3.85 & 6.7 & 12.42 & 18.13 & 24.85 \\
1 & 3 & 3.39 & 6.25 & 11.96 & 17.68 & 23.39 \\
2 & 1 & 3.83 & 6.5 & 11.83 & 17.16 & 22.5 \\
2 & 2 & 3.59 & 6.26 & 11.59 & 16.92 & 22.26 \\
2 & 3 & 3.17 & 5.83 & 11.17 & 16.5 & 21.83 \\
\hline
\end{tabular}

TABLE 29

Downstream natural gas prices for EMEM: different coefficients of inverse demand function $\left(c_{o}\right)$

Next, we vary $c_{1}$ of inverse demand function of electricity. The original function is $P_{j t}^{e}(\cdot)=c_{o}-c_{1} d_{i t}^{e}\left(c_{o}=60, c_{1}=0.1\right)$. Co-efficient $c_{1}$ is changed keeping $c_{0}$ constant. Like in previous analysis, values of $s_{u i t}, z_{m t}, d_{i t}^{e}, g_{n t}, f_{l t}$ and $q_{a w j k t}$ do not change with change in coefficient $c_{1}$. Decrease in co-efficient $c_{1}$ also causes increase in price because $c_{1}$ is a negative co-efficient of inverse demand function. Table 30 shows coal price for region $v$ at equilibrium for different coefficients $\left(c_{1}\right)$. Coal price for region $v_{1}$, time $t_{1}$ for $c_{1}=0.1$ is $59.07 \$ /$ Shortton and for $c_{1}=0.09$ is $65 \$ /$ Shortton.

Table 31 shows electricity price for demand node $i$. Negative co-efficient $c_{1}$ is 


\begin{tabular}{cc|c|c|c|c}
\hline \multicolumn{5}{c}{ Coal price $p_{v t}^{c}$ (\$/Shortton) } \\
\hline$v$ & $t$ & $c_{1}=0.1$ & $c_{1}=0.09$ & $c_{1}=0.06$ & $c_{1}=0.03$ \\
\hline 1 & 1 & 59.07 & 65 & 86 & 106 \\
1 & 2 & 55.16 & 62 & 83 & 105 \\
1 & 3 & 48.32 & 56 & 79 & 103 \\
2 & 1 & 39.78 & 44 & 59 & 74 \\
2 & 2 & 36.90 & 42 & 57 & 73 \\
2 & 3 & 21.86 & 37 & 54 & 72 \\
\hline
\end{tabular}

TABLE 30

Coal price for EMEM: different coefficients of inverse demand function $\left(c_{1}\right)$

\begin{tabular}{cc|c|c|c|c}
\hline \multicolumn{5}{c}{ Electricity price $p_{i i}^{e}(\$ / \mathrm{MWh})$} \\
\hline$i$ & $t$ & $c_{1}=0.1$ & $c_{1}=0.09$ & $c_{1}=0.06$ & $c_{1}=0.03$ \\
\hline 1 & 1 & 28.76 & 31 & 41 & 50 \\
1 & 2 & 26.95 & 30 & 40 & 50 \\
1 & 3 & 23.78 & 27 & 38 & 49 \\
2 & 1 & 28.76 & 31 & 41 & 50 \\
2 & 2 & 26.95 & 30 & 40 & 50 \\
2 & 3 & 23.78 & 27 & 38 & 49 \\
\hline
\end{tabular}

TABLE 31

Electricity price for EMEM: different coefficients of inverse demand function $\left(c_{1}\right)$

decreased from 0.1 to 0.03 . Electricity price for node $i_{1}$, time $t_{1}, c_{1}=0.06$ is 41 $\$ / \mathrm{MWh}$ and $c_{1}=0.03$ is $50 \$ / \mathrm{MWh}$. Decrease in 0.03 to coefficient $c_{1}$ results in an increase of around $9 \$ / \mathrm{MWh}$. Tables 32 and 33 show natural gas transportation and downstream prices. As mentioned previously, due to enormous availability of natural gas capacity production price remains $0.019 \$ / \mathrm{MCF}$ in all cases. The main reason for the increase in shadow price is the increased electricity demand due to decreased value of $c_{1}$. 


\begin{tabular}{cc|c|c|c|c}
\hline \multicolumn{5}{c}{ Ng transportation price $p_{l t}(\$ / \mathrm{MCF})$} \\
\hline$l$ & $t$ & $c_{1}=0.1$ & $c_{1}=0.09$ & $c_{1}=0.06$ & $c_{1}=0.03$ \\
\hline 1 & 1 & 4.09 & 4.53 & 5.87 & 7.23 \\
1 & 2 & 3.83 & 4.3 & 5.72 & 7.15 \\
1 & 3 & 3.37 & 3.89 & 5.44 & 7.01 \\
2 & 1 & 3.81 & 4.23 & 5.48 & 6.75 \\
2 & 2 & 3.57 & 4.01 & 5.33 & 6.67 \\
2 & 3 & 3.15 & 3.63 & 5.08 & 6.55 \\
\hline
\end{tabular}

TABLE 32

Natural gas transportation rates for EMEM: different coefficients of inverse demand function $\left(c_{1}\right)$

\begin{tabular}{cc|c|c|c|c}
\hline \multicolumn{5}{c}{ Ng downstream price $p_{j t}^{g}(\$ / \mathrm{MCF})$} \\
\hline$j$ & $t$ & $c_{1}=0.1$ & $c_{1}=0.09$ & $c_{1}=0.06$ & $c_{1}=0.03$ \\
\hline 1 & 1 & 4.1 & 4.55 & 5.89 & 7.23 \\
1 & 2 & 3.85 & 4.32 & 5.73 & 7.15 \\
1 & 3 & 3.39 & 3.91 & 5.46 & 7.01 \\
2 & 1 & 3.83 & 4.25 & 5.5 & 6.75 \\
2 & 2 & 3.59 & 4.03 & 5.35 & 6.67 \\
2 & 3 & 3.17 & 3.65 & 5.103 & 6.55 \\
\hline
\end{tabular}

TABLE 33

Downstream natural gas prices for EMEM: different coefficients of inverse demand function $\left(c_{1}\right)$ 
Time t1 [700 hours]

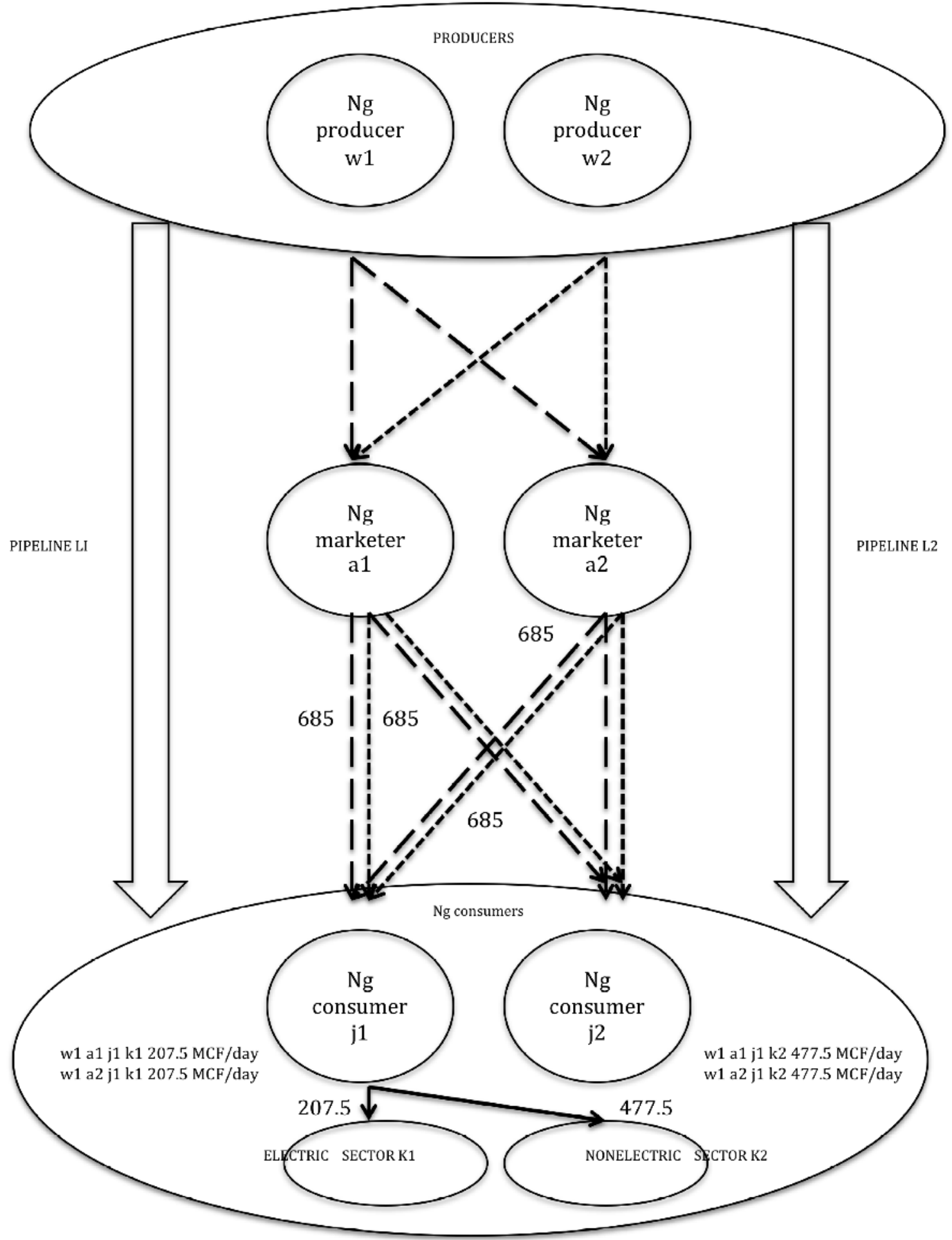

Figure 6. Flow of natural gas from producers to electric and NonE sector 


\section{CHAPTER 5}

\section{CONCLUSION AND FUTURE RESEARCH}

\subsection{Conclusion}

This thesis makes an attempt to explore a way for energy systems that work more efficiently with each other in an integrated manner. The contribution of the thesis is two-fold. First, an equilibrium model is developed using individual optimization problems of players and their market clearing conditions whenever players interact with each other. Second, the model is converted into an MCP for numerical testing. Subsequently, we analyze these numerical results for three models: the model with coal and electricity markets; the model with coal, electricity and natural gas markets; the model with coal, electricity, natural gas markets along with non-electric sector.

Particularly, we solve the equilibrium model as a mixed complementarity problem. The objective is to: 1) create an equilibrium among the players involved in integrated energy system which efficiently governs supply and demand 2) help in decision making and evaluation for a potential energy policy.

Numerical results show that the shadow price of coal, electricity and natural gas perfectly align with those prices reported by EIA [13] and makes model valid for practical use in decision making. The equilibrium model is driven in the direction of maximization of electricity consumers surplus. We analyze the electricity demand and shadow prices for all the three models. It shows that price changes according to demand and is inversely proportional to it. For example, at demand node $i_{1}$ and time $t_{1}$ the elastic demand for electricity is 298 Megawatts when only considering coal as the generation source and the corresponding shadow price of electricity is $\$ 30 /$ MWh. When considering both coal and natural gas as generation sources (but 
without natural gas' non-electric usage) the elastic demand for electricity is 311.69 Megawatts and corresponding shadow price of electricity is $\$ 28.70 / \mathrm{MWh}$. This shows that more electricity is produced when natural gas is made available cause the shadow price of the electricity to drop. It exactly holds true for coal and natural gas markets as well. When non-electric sector is added to the model, the shadow prices slightly increase due to the decrease in production of the electricity (part of the natural gas is used by the non-electric sector) but is less than the shadow price with model that has only the coal and electricity markets. For a cleaner energy policy, natural gas is more environmental friendly than coal. So, this model helps decision makers to decide the quantities of coal and natural gas to be used in their energy system based on shadow prices (output) of the developed EMEM model.

\subsection{Future Research}

There are several future research directions. First, we would like to investigate the theoretical aspect of sensitivity analysis performed on EMEM model by changing various parameters like natural gas pipeline capacity, inverse demand function of electricity, time horizons and the efficiency of generations units in a future study. Second, we would like to extend the EMEM model to imperfect competition environment where electricity generators play Nash-Cournot games among each other, but are price takers of natural gas and coal delivered prices. Third, we would like to discover if coal mine owners have the market power. 


\section{REFERENCES}

[1] Electricity market modeling trends. (2003). Energy Policy, Volume 33, Issue $\%$ Retrieved May, 2005, from http://www.sciencedirect.com/science/article/pii/S0301421503003161.

[2] A critical survey of agent-based wholesale electricity market models. Energy Economics, Volume 30, Issue 4. Retrieved July, 2008, from http://www.sciencedirect.com/science/article/pii/S0140988308000170.

[3] Charles D. Kolstad, David S. Abbey (2002). The effect of market conduct on international steam coal trade. European Economic Review Volume 24, Issue 1. Retrieved July, 2008, http://www.sciencedirect.com/science/article/pii/S0140988315002583

[4] Matt Thompson1, Matt Davison2, and Henning Rasmussen2. Natural gas storage valuation and optimization: A real options application. European Economic Review Volume 28, Issue 3. Retrieved February, 2009, http://www.sciencedirect.com/science/article/pii/S0306261915003013

[5] Kazempour, S.J., Zareipour, H. (2013). Equilibria in an Oligopolistic Market With Wind Power Production. IEEE Transactions of Power Systems. Volume:29 , Issue: 2.

[6] Fuller, J.D., EL-Fouly, T.H.M., Salama, M.M.A.. (2014). Impact of energy storage systems on electricity market equilibrium. IEEE Transactions on Sustainable Energy. Volume:5, Issue: 3 .

[7] B.F. Hobbs (2001). Linear complementarity models of Nash-Cournot competition in Bilateral and POOLCO power market. IEEE Transactions on Power Systems. Volume:16, Issue: 2. 
[8] S.A. Gabriel, S. Kiet, and J. Zhuang (2005). A mixed complementarity-based equilibrium model of natural gas markets. Operations Research. 53(5), 799-818.

[9] A. Quelhas, E. Gil, J. D. McCalley, and S. M. Ryan (2007). A multiperiod generalized network ow model of the U.S. integrated energy system: partI- model description, IEEE Transactions on Power Systems.22(2), 829-836.

[10] C. Haftendorn, F. Holz, and C.V. Hirschhausen. COALMOD-world: a model to assess international coal markets until 2030. DIW Berlin Discus- sion Paper No. 106\% from http://ssrn.com/abstract=1691593 .

[11] Y.J. Wu, and W. Chung. (1997). Assessing the control of energy-related CO2 emissions with a dynamic energy process model. Energy. Volume:22, Issue: 2. .

[12] NEMS, http://www.eia.doe.gov/oiaf/aeo/overview/, 2009

[13] EIA, http://www.eia.gov/

[14] Energy, spectraenergy.com

[15] J. Cardell, C. Hitt, and W. Hogan, Market power and strategic interaction in electricity networks, Resources and Energy Econ., vol. 19, pp. 109137, 1997.

[16] A. Ramos, M. Ventosa, and M. Rivier, Modeling competition in electric energy markets by equilibrium constraints, Util. Policy, vol. 7, pp.233242, 1998.

[17] E. Kahn, Numerical techniques for analyzing market power in electricity, The Elect. J., pp. 3443, July 1998.

[18] U. Helman, B. F. Hobbs, J. B. Cardell, T. Luong, and M. T. Wander, Modeling strategic pricing in bilateral and Poolco electricity markets: A NashCournot approach with applications to US eastern interconnection, in INFORMS National Meeting, Philadelphia, Nov. 710, 1999.

[19] S. Borenstein and J. Bushnell, An empirical analysis of the potential for market power in Californias electricity industry, University of California Energy Institute, Berkeley, CA, PWP-0448, 1998. 
[20] Gabriel, S. A., J. Zhuang, S. Kiet. 2005. A large-scale complementarity model of the North American natural gas market. Energy Economics. Forthcoming.

[21] Avery, W., G. G. Brown, J. A. Rosenkranz, R. K. Wood. 1992. Optimization of purchase, storage and transmission contracts for natural gas utilities. Oper. Res. 10 116-462

[22] Qipeng P.Zheng, Steffen Rebennack, Niko A. Iliadis, and Panos M. Pardalos. Optimization Models in the Natural Gas Industry

[23] De Wolf, D., Y. Smeers. 1996. Optimal dimensioning of pipe net works with applications to gas transmission networks. Oper. Res. 44 596-608.

[24] C. Haftendorn, F. Holz, and C.V. Hirschhausen, "COALMOD-world: a model to assess international coal markets until 2030", DIW Berlin Discussion Paper No. 1067, available at http://ssrn.com/abstract $=1691593,2010$

[25] A quadratic programming model of the Appalachian steam coal market Walter C. Labys and Chin W. Yang

[26] Energy Information Administration 1982, Mathematical Structure and Computer Implementation of the National Coal Model, DOE/El/10128-2, January, Washington, DC.

[27] M. K. LeBlanc, A Transportation Model for the US Coal Industry, report AE Res 76- 10, Cornell University Apicultural Experiment Station, Cornell University, Ithaca, 1976.

[28] Haftendorn, Clemens and Franziska Holz. 2010. Modeling and Analysis of the In-ternational Steam Coal Trade. The Energy Journa31(4):201225.

[29] Rademacher, Maggi. 2008. Development and Perspectives on Supply and Demand in the Global Hard Coal Market." Zeitschrift fur Energiewirtschaft 32(2):6787 
[30] E. M. Gil, A. M. Quelhas, J. D. McCalley, T. V. Voorhis, "Modeling integrated energy transportation networks for analysis of economic efficiency and network interdependencies", Proc. 33rd North American Power Symp., 2003-Oct.

[31] A. M. Quelhas, E. Gil, J. D. McCalley, "Nodal prices in an integrated energy system", Int. J. Critical Infrastructures, vol. 2, no. 1, pp. 50-69, 2006.

[32] Complementarity problems in GAMS and the PATH solver1 by Michael C. Ferris, Todd S. Munson.

[33] Cottle, R.W., Pang, J.S., Stone, R.E., 1992. The Linear Complementarity Problem. Academic Press, Boston.

[34] Dirkse, S.P., Ferris, M.C., 1995a. MCPLIB: a collection of nonlinear mixed complementarity problems. Optimization Methods and Software 5, 319345.

[35] Luo, Z.-Q., Pang, J.S., Ralph, D., 1996. Mathematical Programs with Equilibrium Constraints. Cambridge University Press, Cambridge.

[36] Extensions of GAMS for complementarity problems arising in applied economic analysis.

[37] Complementarity Modeling in Energy Markets By Steven A. Gabriel, Antonio J. Conejo, J. David Fuller, Benjamin F. Hobbs, Carlos Ruiz

[38] Subhash Bhagwat, Philip Robare. Cost of underground coal mining in Illinois Champaign, IL, Illinois State Geographical Survey, November 1982.

[39] The general multimodal network equilibrium problem with elastic demand by Stella Dafermos, 1982.

[40] A Structural Model of Peak-Period Congestion: A Traffic Bottleneck with Elastic Demand Richard Arnott, Andr de Palma and Robin Lindsey the American Economic Review Vol. 83, No. 1 (Mar., 1993), pp. 161-179

[41] An evolutionary game approach to analyzing bidding strategies in electricity markets with elastic demand J Wang, Z Zhou, A Botterud, 2011. 


\section{CURRICULUM VITAE}

NAME:

ADDRESS:

EDUCATION
Swapna Pothabathula

Department of Industrial Engineering

University of Louisville

Louisville, KY 40292

B.Tech. Mechanical Engineering

V.R. Siddhartha engineering College (India)

2013 